\title{
Power Flow Tracing Based Congestion Management Using Differential Evolution in Deregulated Electricity Market
}

\author{
R. Rajathy ${ }^{1}$ and Harish Kumar $^{2}$ \\ ${ }^{1}$ Department of Electrical and Electronics Engineering, Pondicherry Engineering College, \\ Puducherry, India ${ }^{2}$ Department of Physics, Pondicherry Engineering College, Puducherry, India
}

\begin{abstract}
In a restructured electricity market environment, the competition in the production and consumption of electric energy leads to the transmission network operating at or beyond one or more transfer limits. Then the system gets congested, resulting in an increase in the cost of electricity and the system security as well as reliability are said to be in danger. The selection of generators to reschedule their output for effective management of congestion is a crucial task for the system operator. This paper presents a differential evolution algorithm based on power flow tracing approach for selection and rescheduling of active power output. The proposed method is demonstrated on IEEE 30 bus and Indian utility 62 bus systems.
\end{abstract}

Key words: Generator contribution factor, differential evolution, optimal power flow, congestion management, deregulated environment.

\section{Introduction}

In a competitive electricity market, sufficient freedom is provided to the market participants to interact among themselves. Here, both the buyers and sellers try to buy and sell electric power so as to maximize their profit. In such a situation, to meet the desired transactions, power flow in the transmission network violates some of the physical limits of the transmission system. This condition is called the congestion of the transmission network. The undesirable effects of the congestion include volatility and increase of the electricity cost, jeopardizing the system security and reliability. Hence, to maintain the market efficiency, it is very important that the congestion be relieved in a fast, systematic and efficient manner.

The phenomenon of congestion is observed in both regulated and deregulated power systems. In regulated power market, since generation, transmission and distribution are managed by single entity, congestion management is relatively simple. But, in competitive power market, the situation is more complex.

Congestion can be relieved by using available resources like rescheduling of generators, onload tap changers etc. System operators usually prefer these methods to relieve congestion. Further, congestion can also be relieved by providing the information of a particular line getting congested and financial incentives to the consumers so as to adjust the load within the system constraints. In extreme situations, the transactions may be physically curtailed to relieve the congestion. But the system operators keep this as the last option due to its inconvenience to the system users.

Ashwani Kumar et al [1] reported a bibliographical survey on congestion management schemes. Bombard et al [2] reviewed various congestion management schemes and developed a unified framework for mathematical representation of the market dispatch and redispatch problems. Many researchers [3-9] have proposed congestion management using FACTS controllers in deregulated environment. Scheweppe et al [10] laid the foundation of optimal spot pricing on the basis of optimal power flow (OPF). Hogan [11] proposed the contract path and nodal pricing approach for the pool type market structure which provides a mechanism to control the financial risk of congestion induced price variations. Christie et al [12] described three methods of relieving transmission congestion which includes available transfer capability (ATC) based method, price area based method and optimal power flow based method. Among these, optimal power flow based method is being widely used in deregulated market all over the world. Several OPF based congestion management schemes with generation redispatch and curtailment of load have been proposed in the literature [13]. Fang and David [14] proposed a new method as an extension of spot pricing theory in a pool, bilateral and multilateral transactions model. Redispatch of generator output to relieve congestion is also carried out by zonal cluster method [15, 16], relative electrical distance method [17] and generation distribution factor method [18]. In the above methods, generators are redispatched based on their sensitivity factor. Hence the selection of generator is less optimal and it is essential to determine the contribution of each generator to the congested line accurately. Bialek et al [19-21] have proposed power

Received: January $12^{\text {th }}, 2012$. Accepted: August $12^{\text {th }}, 2012$ 
flow tracing approach to determine the contribution of different generators to each transmission line and load in the given network. This method has been used for the transmission pricing in the deregulated market so far. Further, various optimization techniques like genetic algorithm [22], evolutionary programming [23] and particle swarm optimization $[18,24]$ have been applied to the problem of optimal power flow based congestion management. In this paper, we propose two methods for congestion management using Differential Evolution (DE) technique. The first method (method -1 ) uses power flow tracing algorithm to identify the generators contributing to the congested line along with their contribution factors and only these generators are rescheduled. In the second method (method -2), all generators are considered for rescheduling. Both the methods employ DE to optimally redispatch the generators so as to relieve congestion at minimum cost.

\section{Problem Formulation}

The power flow tracing algorithm is a mechanism for tracing the contribution of each user on a transmission system to allocate charges for using the transmission line. It works based on the concepts of Kirchhoff's current law and proportional sharing principle. Two methods are proposed for tracing the power flow namely upstream and downstream algorithms [19-21].

Upstream tracing gives the information about the contribution of each generator to each transmission line and the load, whereas downstream tracing provides the information about the amount of load power shared by the transmission line and the generator. Hence our work employs the upstream tracing algorithm to find the contribution of each individual generator to the flow of power in the transmission line.

The total inflow $P_{i}$ through node $i$ can be expressed as

$$
P_{i}=\sum_{j \in \alpha_{i}^{(u)}}\left|P_{i-j}\right|+P_{G i}=\sum_{j \in \alpha_{i}^{(u)}} c_{j i} P_{j}+P_{G i}
$$

where $i=1,2,3 \ldots n$ and $\alpha_{i}^{(u)}$ is the set of nodes supplying the power directly to the node $i$. $P_{i-j}$ is the power flowing from node $i$ to node $j, P_{G i}$ is the generation power at bus $i$ and $C_{j i}=\left|P_{j-i}\right| / P_{j}$. This equation can be rewritten as

$$
P_{i}-\sum_{j \in \alpha_{i}^{(u)}} c_{j i} P_{j}=P_{G i}
$$

or

$$
A_{u} P=P_{G}
$$

where $A_{u}$ is a $(n \times n)$ upstream distribution matrix . $P$ is the vector of nodal through flows and $P_{G}$ is the vector of nodal generations. The $(i, j)^{\text {th }}$ element of $A_{u}$ is given by

$$
\left[A_{u}\right]_{i j}=\left\{\begin{array}{lc}
1 & \text { for } i=j \\
-c_{j i}=-\left|P_{i-j}\right| / P_{j} & \text { for } j \in \alpha_{i}^{(u)} \\
0 & \text { otherwise }
\end{array}\right.
$$

If $A_{u}^{-1}$ exists, then $P=A_{u}^{-1} P_{G}$ and its $i^{\text {th }}$ element is equal to

$$
P_{i}=\sum_{k=1}^{n}\left[A_{u}^{-1}\right]_{i k} P_{G k} \quad \text { for } \quad i=1,2,3, \ldots n
$$

which shows the contribution of the $k^{\text {th }}$ generator to $i^{\text {th }}$ nodal power.

A line outflow in the line $i-j$ from node $i$ can be calculated using the proportional sharing principle, as

$$
\begin{aligned}
& \left|P_{i-j}\right|=\frac{\left|P_{i-j}\right|}{P_{i}} P_{i}=\frac{\left|P_{i-j}\right|}{P_{i}} \sum_{k=1}^{n}\left[A_{u}^{-1}\right]_{i k} P_{G k} \\
& =\sum_{k=1}^{n} D_{i-j, k}^{G} P_{G k} \quad \text { for all } j \in \alpha_{i}^{(d)}
\end{aligned}
$$


and $D_{i-j, k}^{G}=\left|P_{i-j}\right|\left[A_{u}^{-1}\right]_{i k} / P_{i}$ is the generation contribution factor, which is the flow in the line $i-j$ due to the $k^{\text {th }}$ generator and $\alpha_{i}^{(d)}$ is the set of nodes supplied directly from node $i$. Based on the generation contribution factor, the generators are selected for the process of rescheduling. The amount of rescheduling required is computed by solving the following optimization problem:

Minimize

$$
C C=\sum_{k}^{N_{c}} C_{g} \times \Delta P_{G k}
$$

subject to,

$$
\begin{aligned}
& \sum_{k}^{N_{c}}\left(P_{G k}^{0}+\Delta P_{G k}\right)+\sum_{l, l \neq k}^{N_{g}} P_{G k}^{0}=\sum_{m}^{N_{d}} P_{d m}^{0}+P_{L} \\
& \sum_{k}^{N_{c}} P_{G k}^{f}+\sum_{l, l \neq k}^{N_{g}} P_{G k}^{0}=\sum_{m}^{N_{d}} P_{d m}^{0}+P_{L} \\
& P_{G k}^{0}-P_{G k}^{\min }=\Delta P_{G k}^{\min } \leq \Delta P_{G k} \leq \Delta P_{G k}^{\max }=P_{G k}^{\max }-P_{G k}^{0} \\
& S_{i, j} \leq S_{i, j}^{\max } \\
& V_{i}^{\min } \leq V_{i} \leq V_{i}^{\max } \\
& \delta_{i}^{\min } \leq \delta_{i} \leq \delta_{i}^{\max }
\end{aligned}
$$

where

$C C=$ total congestion cost to relieve congestion

$N_{g}=$ total number of generators.

$N_{c}=$ total number of participating generators in the process of rescheduling $\left(N_{c} \subset N_{g}\right)$.

$k=$ participating generator.

$l=$ non participating generator.

$N_{s}=$ number of transmission line in the system.

$N_{d}=$ total number of loads in the system

$m=$ individual load at each bus

$P_{L}=$ total transmission losses

$P_{G k}^{0}=$ active power generated by the $k^{\text {th }}$ generator as determined by the system operator.

$P_{G k}^{f}=$ active power generated by the $k^{\text {th }}$ generator after the process of rescheduling.

$P_{d m}^{0}=$ active power consumed by the $m^{\text {th }}$ load as determined by the system operator.

$P_{G k}^{\min }, P_{G k}^{\max }=$ minimum and maximum limits of the $k^{\text {th }}$ generator.

$\Delta P_{G k}=$ change in real power adjustment at bus $k$.

$\Delta P_{G k}^{\min }, \Delta P_{G k}^{\max }=$ minimum and maximum limits of the change in real power adjustment of the $k^{\text {th }}$ generator.

$C_{g}=$ incremental and decremental price bids submitted by generators at which the generators

are willing to adjust their real power outputs to relieve congestion.

$S_{i j}=$ MVA power flow in the line $i-j$.

$S_{i j}^{\max }=$ maximum MVA limit of the line $i-j$.

$V_{i}, \delta_{i}=$ voltage and angle at bus $i$.

During the process of optimization the power balance and system losses are taken care by the slack bus generator. 


\section{Differential Evolution}

Differential Evolution is an optimization algorithm developed by Storn and Price, which solves real-valued problems based on the principles of natural evolution $[25,26]$. DE uses a population $P$ of size $N_{p}$, composed of floating point encoded individuals that evolve over $G$ generations to reach an optimal solution. Each individual $X_{i}$ is a vector that contains as many parameters as the problem decision variables $D$. The population size $N_{p}$ is an algorithm control parameter selected by the user which remains constant throughout the optimization process.

$$
\begin{aligned}
& P^{(G)}=\left[X_{i}^{(G)}, \ldots . ., X_{N_{P}}^{(G)}\right] \\
& X_{i}^{(G)}=\left[X_{1, i}^{(G)}, \ldots, X_{D, i}^{(G)}\right]^{T}, i=1, \ldots, N_{p}
\end{aligned}
$$

Here $X_{i}^{(G)}$ refers to $i^{\text {th }}$ individual vector in the $G^{\text {th }}$ generation.

The ${ }^{i}$ optimization process in differential evolution is carried out with three basic operations viz, mutation, crossover and selection. This algorithm starts by creating an initial population of $N_{p}$ vectors. Random values are assigned to each decision parameter in every vector according to

$$
X_{j, i}^{(0)}=X_{j}^{\min }+\eta_{j}\left(X_{j}^{\max }-X_{j}^{\min }\right)
$$

where $i=1, \ldots, N_{p}$ and $j=1, \ldots . D ; X_{j}^{\min }$ and $X_{j}^{\max }$ are the lower and upper bounds of the $j^{\text {th }}$ decision parameter; and $\eta_{j}$ is an uniformly distributed random number within [0,1] generated a new for each value of $j . X_{j, i}^{(0)}$ is the $j^{\text {th }}$ parameter of the $i^{\text {th }}$ individual of the initial population.

The mutation operator creates mutant vectors $\left(X_{i}{ }^{\prime}\right)$ by perturbing a randomly selected vector $\left(X_{a}\right)$ with the difference of two other randomly selected vectors $\left(X_{b}\right.$ and $\left.X_{c}\right)$.

$$
X_{i}^{\prime(G)}=X_{a}^{(G)}+F\left(X_{b}^{(G)}-X_{c}^{(G)}\right), \quad i=1, \ldots, N_{p}
$$

where $X_{a}, X_{b}$ and $X_{c}$, are randomly chosen vectors $\in\left\{1, \ldots, N_{p}\right\}$ and $a \neq b \neq c \neq i$. $X_{a}, X_{b}$ and $X_{c}$ are selected a new for each parent vector. The scaling constant $(F)$ is an algorithm control parameter used to control the perturbation size in the mutation operator and improve algorithm convergence.

The crossover operation generates trial vectors $\left(X_{i}^{\prime \prime}\right)$ by mixing the parameters of the mutant vectors with the target vectors $\left(X_{i}\right)$, according to a selected probability distribution.

$$
X_{j, i}^{\prime \prime(G)}=\left\{\begin{array}{l}
X_{j, i}^{\prime(G)}, \text { if } \eta_{j}^{\prime} \leq C_{R} \text { or } j=q \\
X_{j, i}^{(G)}, \text { otherwise }
\end{array}\right.
$$

where $i=1, \ldots, N_{p}$ and $j=1, \ldots . D ; q$ is a randomly chosen index $\in\left\{1, \ldots, N_{p}\right\}$ that guarantees that the trial vector gets at least one parameter from the mutant vector; $\eta_{j}^{\prime}$ is a uniformly distributed random number within $[0,1]$ generated newly for each value of $j . X_{j, i}^{(G)}$, $X_{j, i}^{\prime(G)}$ and $X_{j, i}^{\prime \prime(G)}$ are the $j^{\text {th }}$ parameter of the $i^{\text {th }}$ target vector, mutant vector, and trial vector at generation $G$, respectively. Finally, the selection operator determines the population by choosing between the trial vectors and their predecessors (target vectors) those individuals that present a better fitness or are more optimal. 


$$
X_{i}^{(G+1)}=\left\{\begin{array}{l}
X_{i}^{\prime \prime(G)}, \text { if } f\left(X_{i}^{\prime \prime(G)}\right) \leq f\left(X_{i}^{(G)}\right), i=1, \ldots . ., N_{p} \\
X_{i}^{(G)}, \text { otherwise }
\end{array}\right.
$$

The optimization process is repeated for several generations, allowing individuals to improve their fitness as they explore the solution space in the search for optimal values.

$\mathrm{DE}$ has three essential control parameters: scaling factor $(F)$, crossover constant $\left(C_{R}\right)$ and population size $\left(N_{P}\right)$. The scaling factor is a value in the range $(0,2)$ that controls the amount of perturbation in the mutation process. The crossover constant is a value in the range $(0,1)$ that controls the diversity of the population. The population size determines the number of individuals in the population and provides the algorithm enough diversity to search the solution space.

$\mathrm{DE}$ offers several variants or strategies for optimization. These can be denoted by $D E / x / y / z$, where $x$ refers to the vector used to generate mutant vectors, $y$ the number of difference vectors used in the mutations process and $z$ the crossover scheme used in the crossover operation. There are ten different working strategies proposed by Price and Storn [25, 26]. The working algorithm used in this paper is the seventh strategy of DE (i.e.) $D E$ / rand / / / bin in which $D E$ represents differential evolution, rand is any randomly chosen vector for perturbations, 1 represents the number of difference vectors to be perturbed and bin is the binomial type of crossover used. The DE simulation parameters employed in the present study are: population $\operatorname{size}\left(N_{p}\right)=40$, scaling factor $(F)=0.6$, crossover constant $\left(C_{R}\right)=0.8$, maximum iteration $\left(i t_{\max }\right)=100$.

\section{Proposed Algorithm}

Generators for the congestion management are selected based on generator contribution factor and rescheduled using DE as outlined in figure (1).

\section{Case Studies and Results}

\section{A. 3 bus system}

A sample 3 bus system [27] is considered for explaining the power flow tracing algorithm. The system shown in figure 2 has two generators at buses 1 and 3, one load at bus 2, and three transmission lines. The active and reactive power flows obtained through AC power flow program is shown in figure 3. Figure 4 shows the lossless real power flow obtained from lossy flow of figure 3. Using equation (4), the upstream matrix $\left(A_{u}\right)$ for the above system is found to be:

$$
A_{u}=\left(\begin{array}{ccc}
1 & 0 & 0 \\
\frac{-175.165}{214.135} & 1 & \frac{-233.955}{233.955} \\
\frac{-38.9615}{214.135} & 0 & 1
\end{array}\right)
$$

Inverting the above matrix, we get

$$
A_{u}^{-1}=\left(\begin{array}{ccc}
1 & 0 & 0 \\
1 & 1 & 1 \\
0.1819 & 0 & 1
\end{array}\right)
$$

Equation (6) helps to determine the way in which the line flows are supplied by the individual generators. The flow in line say, from bus $3 \rightarrow 2$, can be calculated as

$$
\left(\frac{233.955}{233.955}\right) \times 0.1819 \times 214.135=38.9512 \mathrm{MW}
$$

from $G_{1}$ and 


$$
\left(\frac{233.955}{233.955}\right) \times 1 \times 194.985=194.985 \mathrm{MW}
$$

from $G_{3}$. Similarly, the flows in all other lines are calculated and given in Table 1.

Table 1. Actual contributions of generators to the transmission lines of a 3 bus system

\begin{tabular}{|c|c|c|c|c|c|}
\hline \multirow{2}{*}{$\begin{array}{l}\text { Lines connected } \\
\text { between } \\
\text { the buses }\end{array}$} & \multirow{2}{*}{$\begin{array}{l}\text { Actual Power } \\
\text { flows } \\
\text { (MW) }\end{array}$} & \multirow{2}{*}{$\begin{array}{l}\text { Contribution of } \\
\text { Generator } \\
G_{1}(\mathrm{MW})\end{array}$} & \multirow{2}{*}{$\begin{array}{l}\text { Contribution of } \\
\text { Generator } \\
G_{3}(\mathrm{MW})\end{array}$} & \multicolumn{2}{|c|}{$\begin{array}{l}\text { Contribution } \\
\text { Factor }(D)\end{array}$} \\
\hline & & & & $G_{1}$ & $G_{3}$ \\
\hline $1-2$ & 175.16 & 175.16 & 0.0000 & 0.8180 & 0.0000 \\
\hline $1-3$ & 38.9695 & 38.9695 & 0.0000 & 0.1819 & 0.0000 \\
\hline $3-2$ & 233.955 & 38.9512 & 194.985 & 0.1819 & 1.0000 \\
\hline
\end{tabular}

\section{B. IEEE 30 bus system}

The test system shown in figure 5 has three areas with two generators in each area. It has 41 transmission lines, 23 load buses with a load demand of 189.2 MW. Price bids submitted by the independent power producers are given in Table 2. Incremental and decremental cost is assumed to be same and it is taken slightly more than the marginal cost [13]. The proposed method is applied to this test system as discussed below.

Table 2. Price bids submitted by the independent power producers

\begin{tabular}{|c|c|}
\hline $\begin{array}{c}\text { Generator } \\
\text { number }\end{array}$ & $\begin{array}{c}\text { Incremental / decremental } \\
\text { bid }(\$ / \mathrm{MWh})\end{array}$ \\
\hline$G_{1}$ & 35 \\
\hline$G_{2}$ & 40 \\
\hline$G_{3}$ & 42 \\
\hline$G_{4}$ & 44 \\
\hline$G_{5}$ & 48 \\
\hline$G_{6}$ & 36 \\
\hline
\end{tabular}

Table 3. Active power flow contribution factor of generators to the transmission lines single line contingency

\begin{tabular}{|c|c|c|c|c|c|c|c|c|}
\hline \multirow{2}{*}{$\begin{array}{c}\text { Line } \\
\text { number }\end{array}$} & \multirow{2}{*}{$\begin{array}{c}\text { From } \\
\text { bus }\end{array}$} & To & \multicolumn{7}{|c|}{ bus } & $G_{1}$ & $G_{2}$ & $G_{3}$ & $G_{4}$ & $G_{5}$ & $G_{6}$ \\
\hline 1 & 1 & 2 & 0.559 & 0.000 & 0.000 & 0.000 & 0.000 & 0.000 \\
\hline 2 & 1 & 3 & 0.441 & 0.000 & 0.000 & 0.000 & 0.000 & 0.000 \\
\hline 3 & 2 & 4 & 0.109 & 0.194 & 0.000 & 0.000 & 0.000 & 0.000 \\
\hline 4 & 2 & 5 & 0.165 & 0.294 & 0.000 & 0.000 & 0.000 & 0.000 \\
\hline 5 & 2 & 6 & 0.141 & 0.253 & 0.000 & 0.000 & 0.000 & 0.000 \\
\hline 6 & 3 & 4 & 0.384 & 0.000 & 0.000 & 0.000 & 0.000 & 0.000 \\
\hline 7 & 4 & 6 & 0.333 & 0.132 & 0.000 & 0.000 & 0.000 & 0.000 \\
\hline 8 & 4 & 12 & 0.043 & 0.017 & 0.000 & 0.000 & 0.000 & 0.000 \\
\hline 9 & 5 & 7 & 0.165 & 0.294 & 0.000 & 0.000 & 0.000 & 0.000 \\
\hline 10 & 7 & 6 & 0.010 & 0.017 & 0.000 & 0.000 & 0.000 & 0.000 \\
\hline & & \multicolumn{7}{|c|}{ Continued on next page } \\
\hline
\end{tabular}


Table 3. Continued from previous page

\begin{tabular}{|c|c|c|c|c|c|c|c|c|}
\hline \multirow{2}{*}{$\begin{array}{c}\text { Line } \\
\text { number }\end{array}$} & \multirow{2}{*}{$\begin{array}{l}\text { From } \\
\text { bus }\end{array}$} & \multirow{2}{*}{$\begin{array}{l}\text { To } \\
\text { bus }\end{array}$} & \multicolumn{6}{|c|}{ Contribution factor $(D)$} \\
\hline & & & $G_{1}$ & $G_{2}$ & $G_{3}$ & $G_{4}$ & $G_{5}$ & $G_{6}$ \\
\hline 11 & 6 & 8 & 0.251 & 0.209 & 0.000 & 0.000 & 0.000 & 0.000 \\
\hline 12 & 6 & 9 & 0.103 & 0.085 & 0.000 & 0.000 & 0.000 & 0.000 \\
\hline 13 & 6 & 10 & 0.059 & 0.049 & 0.000 & 0.000 & 0.000 & 0.000 \\
\hline 14 & 6 & 28 & 0.031 & 0.026 & 0.000 & 0.000 & 0.000 & 0.000 \\
\hline 15 & 28 & 8 & 0.031 & 0.026 & 0.000 & 0.000 & 0.000 & 0.023 \\
\hline 16 & 9 & 11 & 0.000 & 0.000 & 0.000 & 0.000 & 0.000 & 0.000 \\
\hline 17 & 9 & 10 & 0.103 & 0.085 & 0.000 & 0.000 & 0.000 & 0.000 \\
\hline 18 & 10 & 20 & 0.037 & 0.031 & 0.000 & 0.105 & 0.000 & 0.000 \\
\hline 19 & 10 & 17 & 0.003 & 0.002 & 0.000 & 0.008 & 0.000 & 0.000 \\
\hline 20 & 10 & 21 & 0.077 & 0.064 & 0.000 & 0.218 & 0.000 & 0.000 \\
\hline 21 & 22 & 10 & 0.000 & 0.000 & 0.000 & 0.459 & 0.000 & 0.000 \\
\hline 22 & 13 & 12 & 0.000 & 0.000 & 1.000 & 0.000 & 0.000 & 0.000 \\
\hline 23 & 12 & 14 & 0.007 & 0.003 & 0.157 & 0.000 & 0.000 & 0.000 \\
\hline 24 & 12 & 15 & 0.011 & 0.004 & 0.256 & 0.000 & 0.000 & 0.000 \\
\hline 25 & 12 & 16 & 0.013 & 0.005 & 0.306 & 0.000 & 0.000 & 0.000 \\
\hline 26 & 15 & 18 & 0.006 & 0.002 & 0.137 & 0.000 & 0.213 & 0.000 \\
\hline 27 & 23 & 15 & 0.000 & 0.000 & 0.000 & 0.000 & 0.398 & 0.000 \\
\hline 28 & 16 & 17 & 0.009 & 0.004 & 0.217 & 0.000 & 0.000 & 0.000 \\
\hline 29 & 18 & 19 & 0.004 & 0.002 & 0.090 & 0.000 & 0.140 & 0.000 \\
\hline 30 & 20 & 19 & 0.022 & 0.018 & 0.000 & 0.063 & 0.000 & 0.000 \\
\hline 31 & 22 & 21 & 0.000 & 0.000 & 0.000 & 0.365 & 0.000 & 0.000 \\
\hline 32 & 22 & 24 & 0.000 & 0.000 & 0.000 & 0.176 & 0.000 & 0.000 \\
\hline 33 & 23 & 24 & 0.000 & 0.000 & 0.000 & 0.000 & 0.434 & 0.000 \\
\hline 34 & 25 & 24 & 0.000 & 0.000 & 0.000 & 0.000 & 0.000 & 0.094 \\
\hline 35 & 25 & 26 & 0.000 & 0.000 & 0.000 & 0.000 & 0.000 & 0.195 \\
\hline 36 & 27 & 25 & 0.000 & 0.000 & 0.000 & 0.000 & 0.000 & 0.289 \\
\hline 37 & 27 & 29 & 0.000 & 0.000 & 0.000 & 0.000 & 0.000 & 0.321 \\
\hline 38 & 27 & 30 & 0.000 & 0.000 & 0.000 & 0.000 & 0.000 & 0.368 \\
\hline 39 & 27 & 28 & 0.000 & 0.000 & 0.000 & 0.000 & 0.000 & 0.023 \\
\hline 40 & 29 & 30 & 0.000 & 0.000 & 0.000 & 0.000 & 0.000 & 0.206 \\
\hline
\end{tabular}

\section{B.1. Single line contingency}

The line connecting buses 14 and 15 (line 24) in area 2 is considered to be out of service due to which the line connecting buses 6 and 8 (line 11) gets congested. Using power flow tracing method we located the generators contributing to the congested line 11 as $G_{1}$ and $G_{2}$ (figure 6). The contribution factor of generators $G_{1}$ and $G_{2}$ to the line 11 are found to be 0.251 and 0.209 respectively (Table 3 ). The output of the generators $G_{1}$ and $G_{2}$ is rescheduled by employing a differential evolution based optimal power flow algorithm shown in figure 1.

The amount of power flowing in each line during and after congestion is shown in figure 7. After relieving congestion, the power flow through line 11 lies well within the maximum limit. The contribution factor of $G_{1}$ and $G_{2}$ to the line 11 is changed to 0.239 and 0.234 respectively.

Figure 8 shows the rescheduled powers of different generators by method -1 and method - 2. In method - 2, all the six generators $\left(G_{1}, G_{2}, G_{3}, G_{4}, G_{5}\right.$ and $\left.G_{6}\right)$ need to be rescheduled to relieve the congestion. But, by applying the first method, it was possible to relieve the congestion by rescheduling only two generators $\left(G_{1}\right.$ and $\left.G_{2}\right)$. 
The convergence graph in figure 9 shows that the first method gives lesser congestion cost $(225.8991 \$ / \mathrm{h})$ than the second $(305.4972 \$ / \mathrm{h})$, thereby benefiting the consumers. Figure 10 shows the voltage magnitude and phase angle for each bus after relieving congestion. It can be seen that they are within the permissible limits ensuring system security and stability.

\section{Indian utility 62 bus system}

The system has 19 generators, $89(220 \mathrm{kV})$ transmission lines, 11 tap changing transformers with a power demand of $3304 \mathrm{MW}$. The system is divided into 3 areas with six generators in area 1 and area 3 respectively, whereas area 2 has seven generators as shown in figure 11 . The line data and bus data for the present system are taken from [28]. Price bids submitted by the independent power producers are given in Table 4.

\section{C.1. Multiline contingency}

We have considered the line connecting buses 61 and 62 between area 1 and area 2 (line 88) to be out of service due to which the lines connecting buses 31-32 (line 43), 39-42 (line 58) and 55-58 (line 78) get congested.

Using power flow tracing method, we located the generators contributing to the congested lines 43,58 and 78 as $G_{9}, G_{10}, G_{11}, G_{12}, G_{13}$ and $G_{14}$ as shown in figure 12 . The contribution factor of the generators to the congested lines 43, 58 and 78 is given in Table 5 . From Table 5, it is found that the generators $G_{12}, G_{13}$ and $G_{14}$ are contributing more effectively than the other generators. Hence these generators are selected by the system operator for the process of rescheduling to relieve the congestion efficiently.

The amount of power flowing in each line during and after congestion is shown in figure 13. After relieving congestion, the power flow through the congested lines 43, 58 and 78 lies well within the maximum limit.

Figure 14 shows the rescheduled powers of different generators by method -1 and method -2 . It is inferred from figure 14 that in method -2 , seven generators $\left(G_{10}, G_{11}, G_{12}, G_{13}\right.$, $G_{14}, G_{15}$ and $G_{16}$ ) are rescheduled to relieve the congestion. But, by applying the first method, it was possible to relieve the congestion by rescheduling only three generators $-G_{12}$, $G_{13}$ and $G_{14}$.

The convergence graph in figure 15 shows that the first method gives lesser congestion cost $(6805.1103 \% \mathrm{~h}$, where 'is the symbol for Indian currency rupee and $\mathrm{h}$ represents hour) than the second $(7114.0459 \% \mathrm{~h})$, thereby benefiting the consumers. Figure 16 shows the voltage magnitude and phase angle for each bus after relieving congestion. It can be seen that they are within the permissible limits ensuring system security and stability.

\section{Conclusions}

This paper presents an OPF based method for congestion management. The generators to be rescheduled are identified based on active power flow contribution factor using power flow tracing algorithm. The congestion cost is minimized using differential evolution optimization technique. It is found that the power flow tracing method directly provides the contribution of each generator to the congested line. This results in lesser number of generators participating in the process of rescheduling thereby reducing the congestion cost to a larger extent. The proposed algorithm is illustrated on IEEE 30 bus and Indian utility 62 bus system. It is found that differential evolution gives better optimal solutions when used with power flow tracing algorithm.

Table 4. Price bids submitted by the independent power producers

\begin{tabular}{|l|c|c|c|c|c|c|c|c|c|c|}
\hline $\begin{array}{l}\text { Generator } \\
\text { number }\end{array}$ & $G_{1}$ & $G_{2}$ & $G_{3}$ & $G_{4}$ & $G_{5}$ & $G_{6}$ & $G_{7}$ & $G_{8}$ & $G_{9}$ & $G_{10}$ \\
\hline $\begin{array}{l}\text { Incremental/ } \\
\text { decremental bid } \\
\text { (/MWh) }\end{array}$ & 1410 & 1645 & 2115 & 1450 & 1570 & 1555 & 1622 & 1370 & 1550 & 2100 \\
\hline $\begin{array}{l}\text { Generator } \\
\text { number }\end{array}$ & $G_{11}$ & $G_{12}$ & $G_{13}$ & $G_{14}$ & $G_{15}$ & $G_{16}$ & $G_{17}$ & $G_{18}$ & $G_{19}$ & - \\
\hline $\begin{array}{l}\text { Incremental/ } \\
\text { decremental bid } \\
\text { (/MWh) }\end{array}$ & 2170 & 2200 & 1850 & 1680 & 1540 & 1720 & 1600 & 1680 & 1745 & - \\
\hline
\end{tabular}




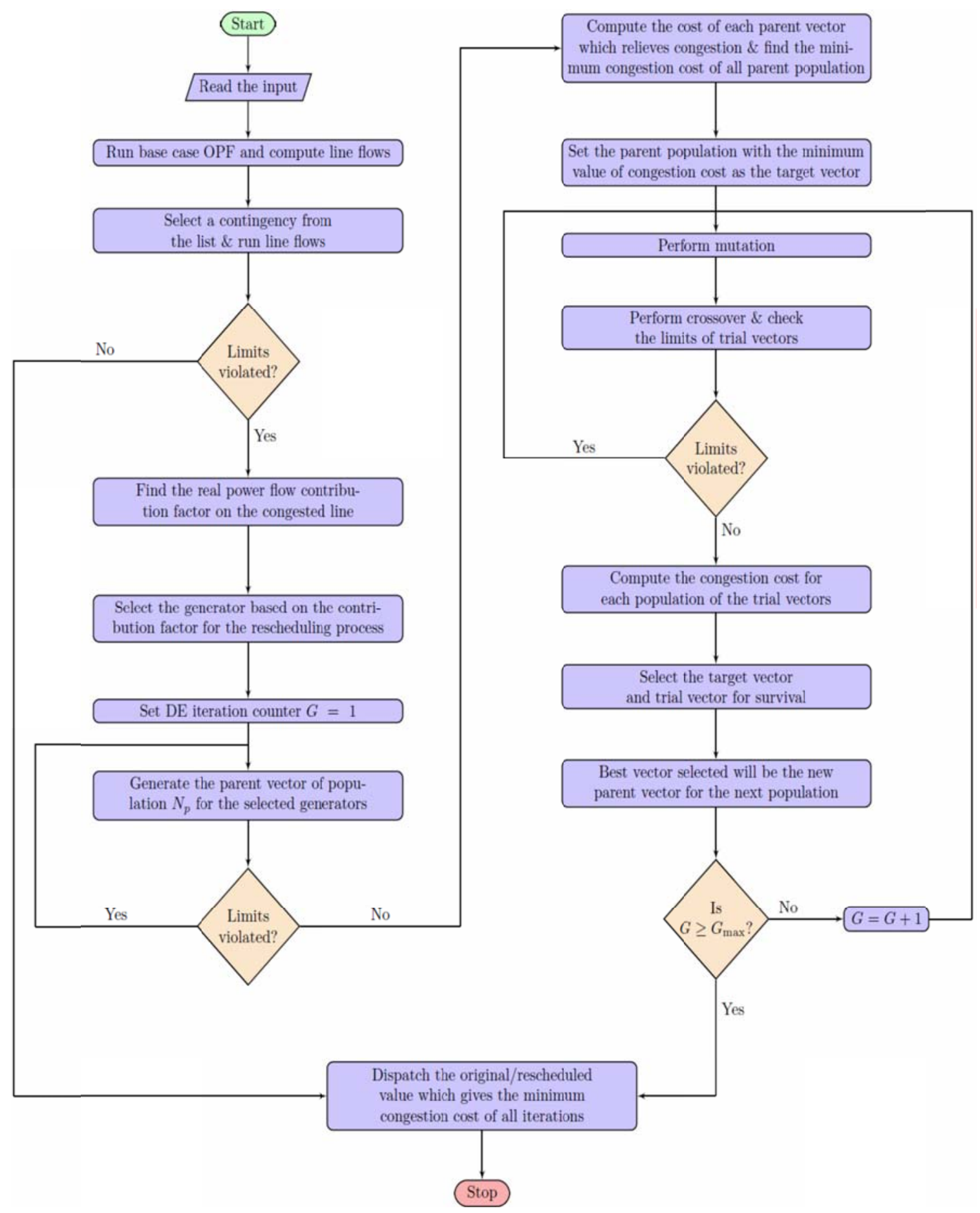

Figure 1. Flow chart of the proposed algorithm 


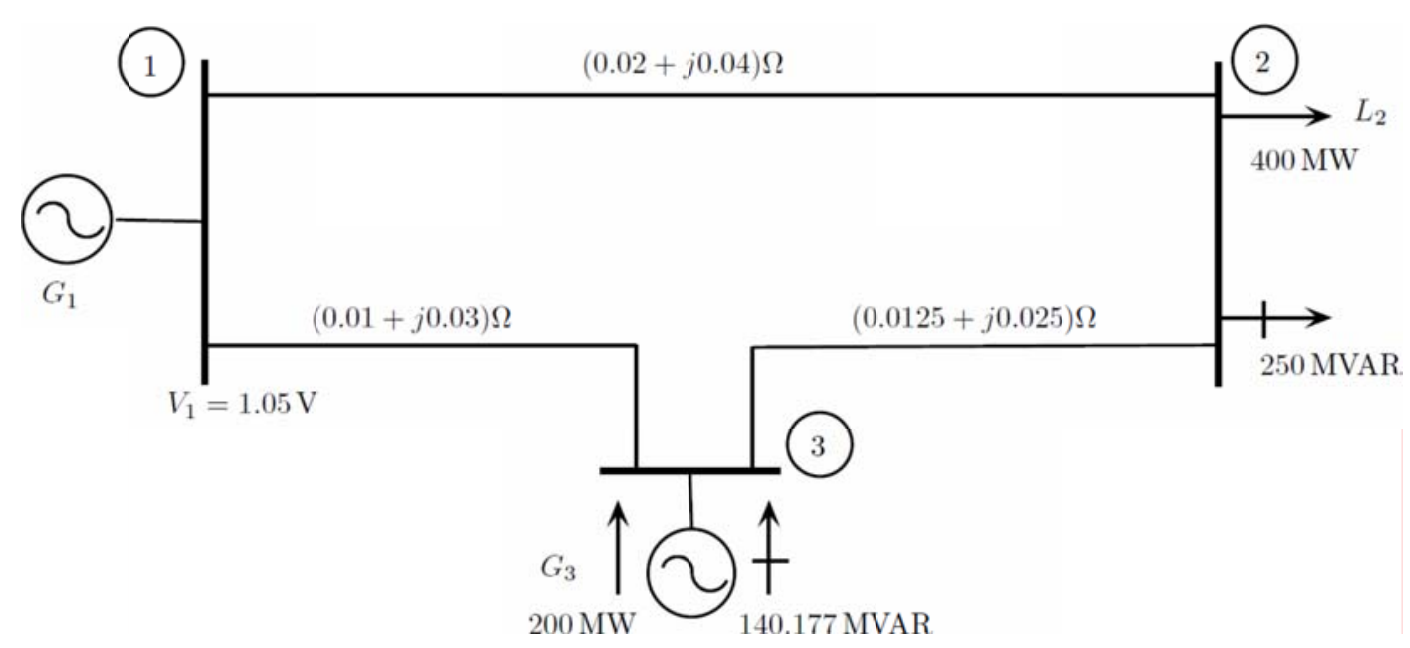

Figure 2. One line diagram of 3 bus system

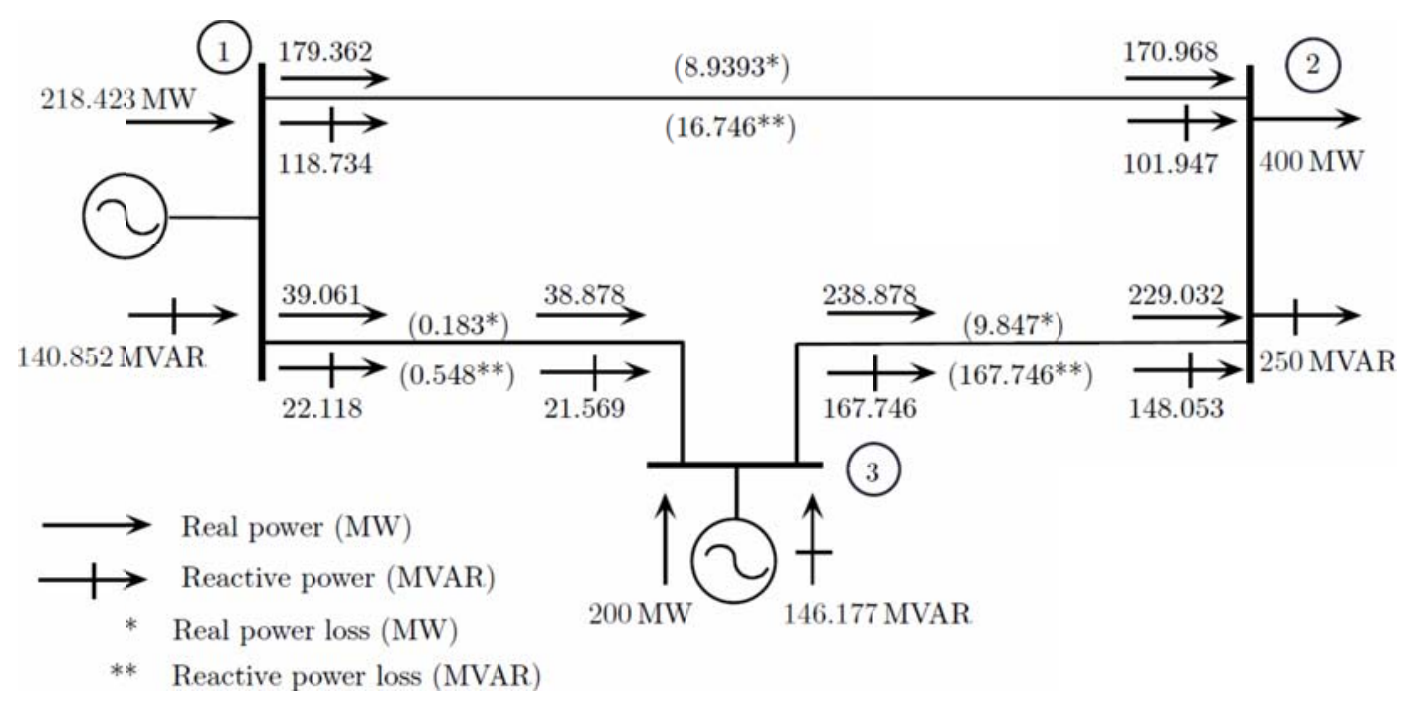

Figure 3. Power flow diagram of 3 bus system

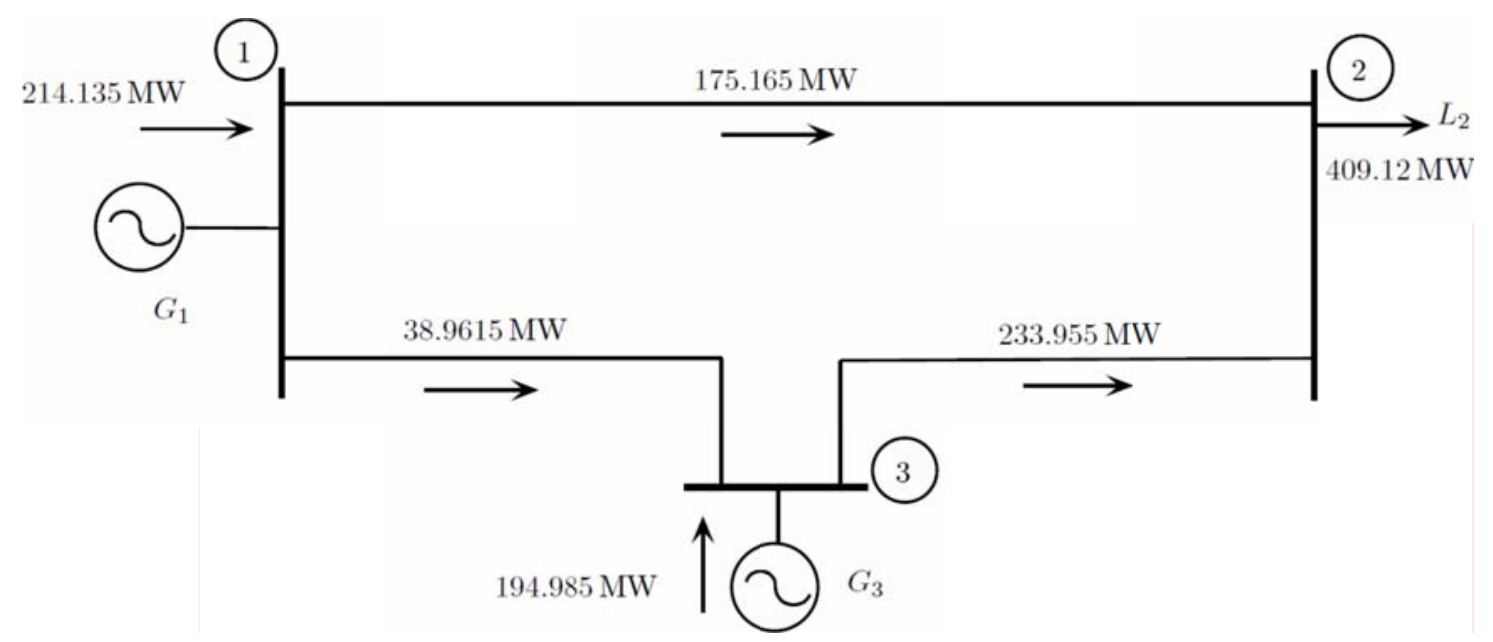

Figure 4. Lossless network of 3 bus system 


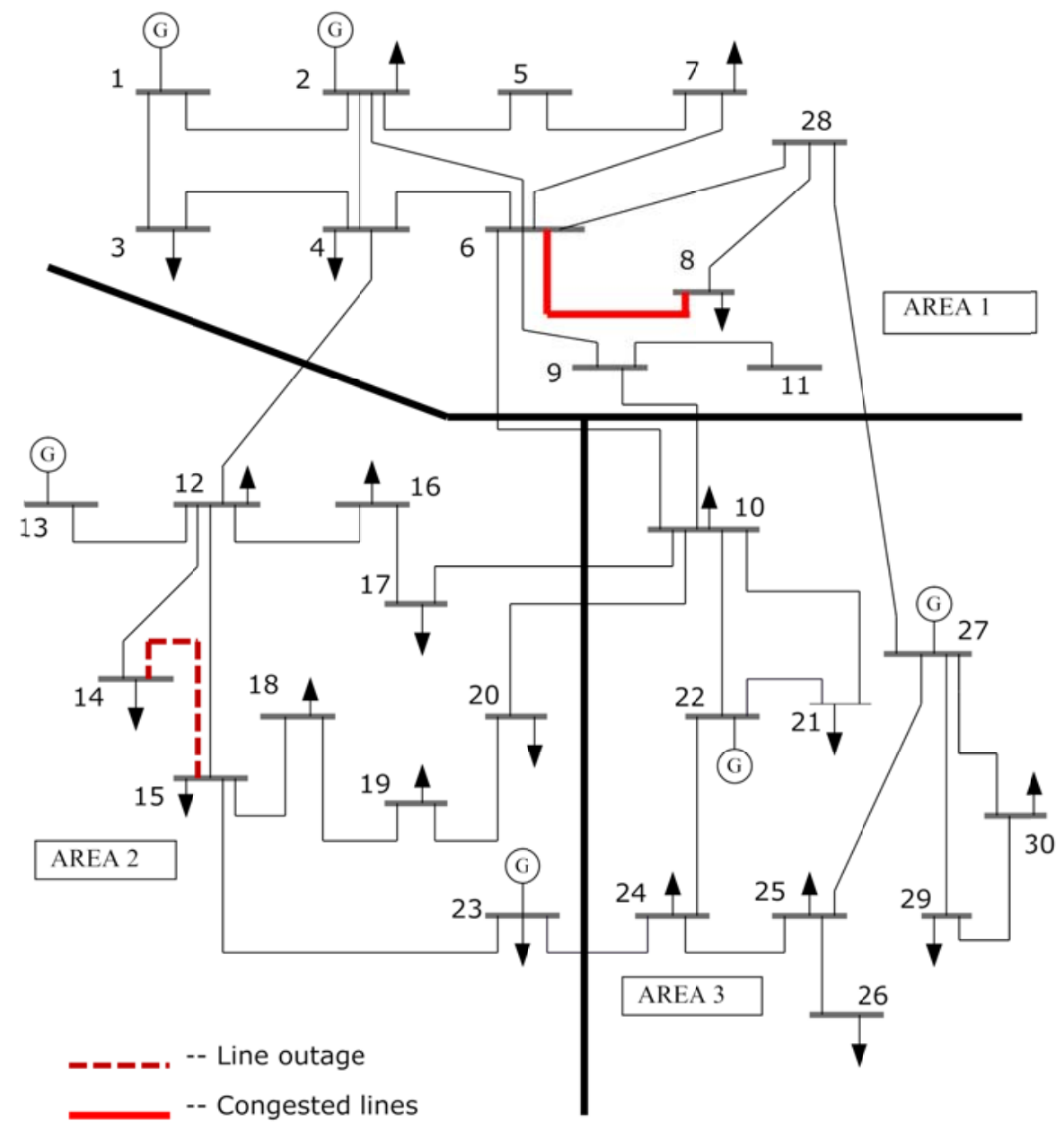

Figure 5. One line diagram of IEEE 30 bus system showing line outages and congestedl lines

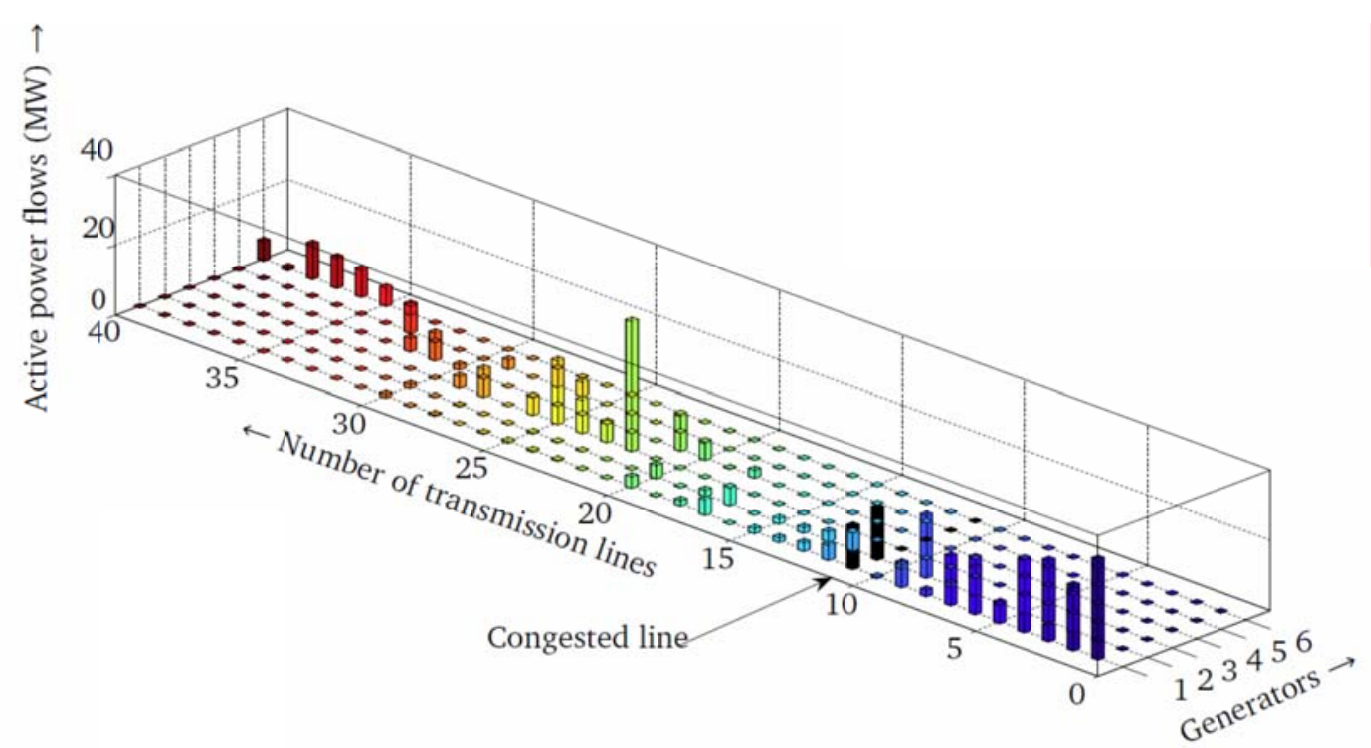

Figure 6. Contribution of generators to each transmission line 


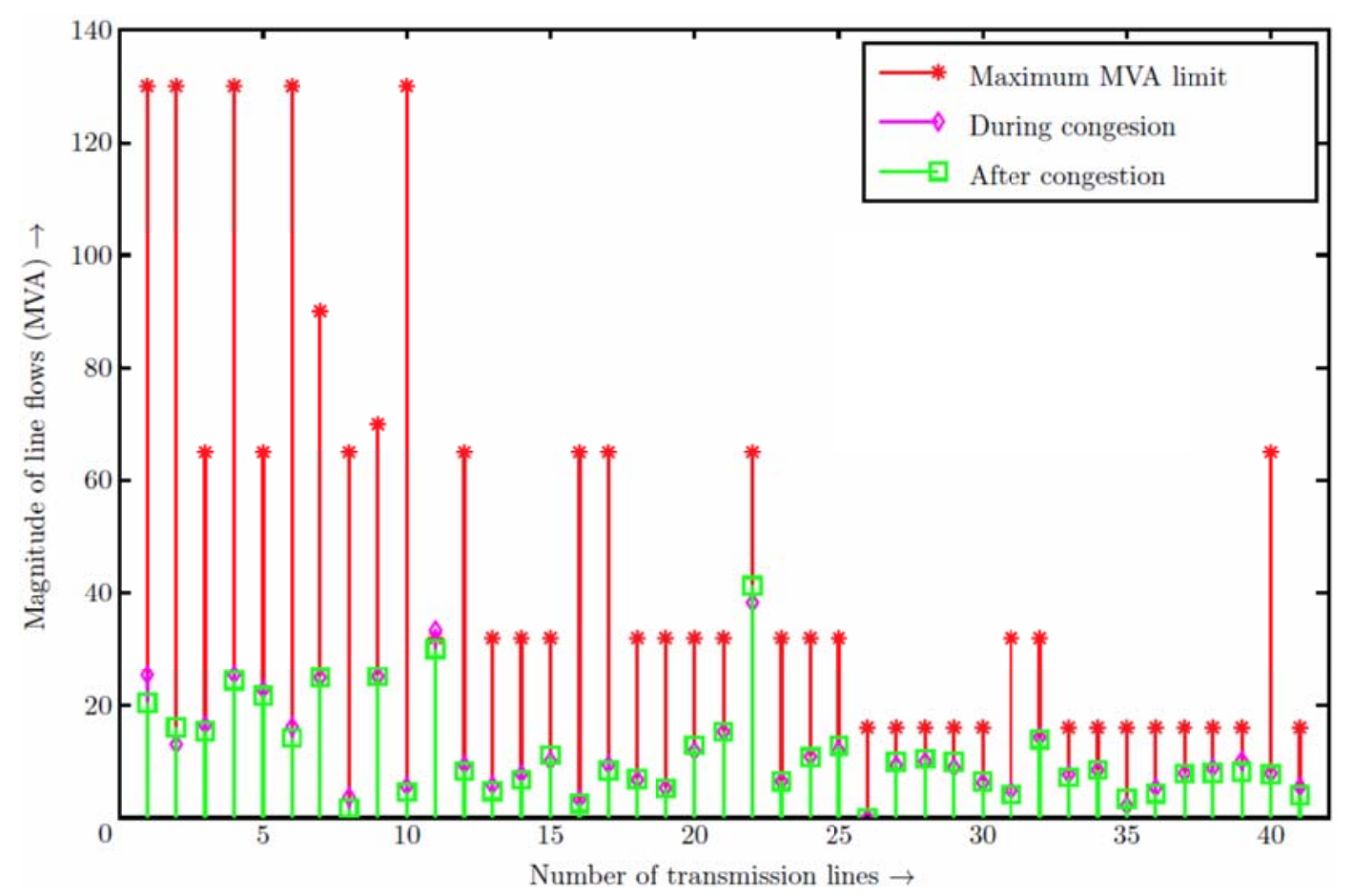

Figure 7. Power flows in each transmission line

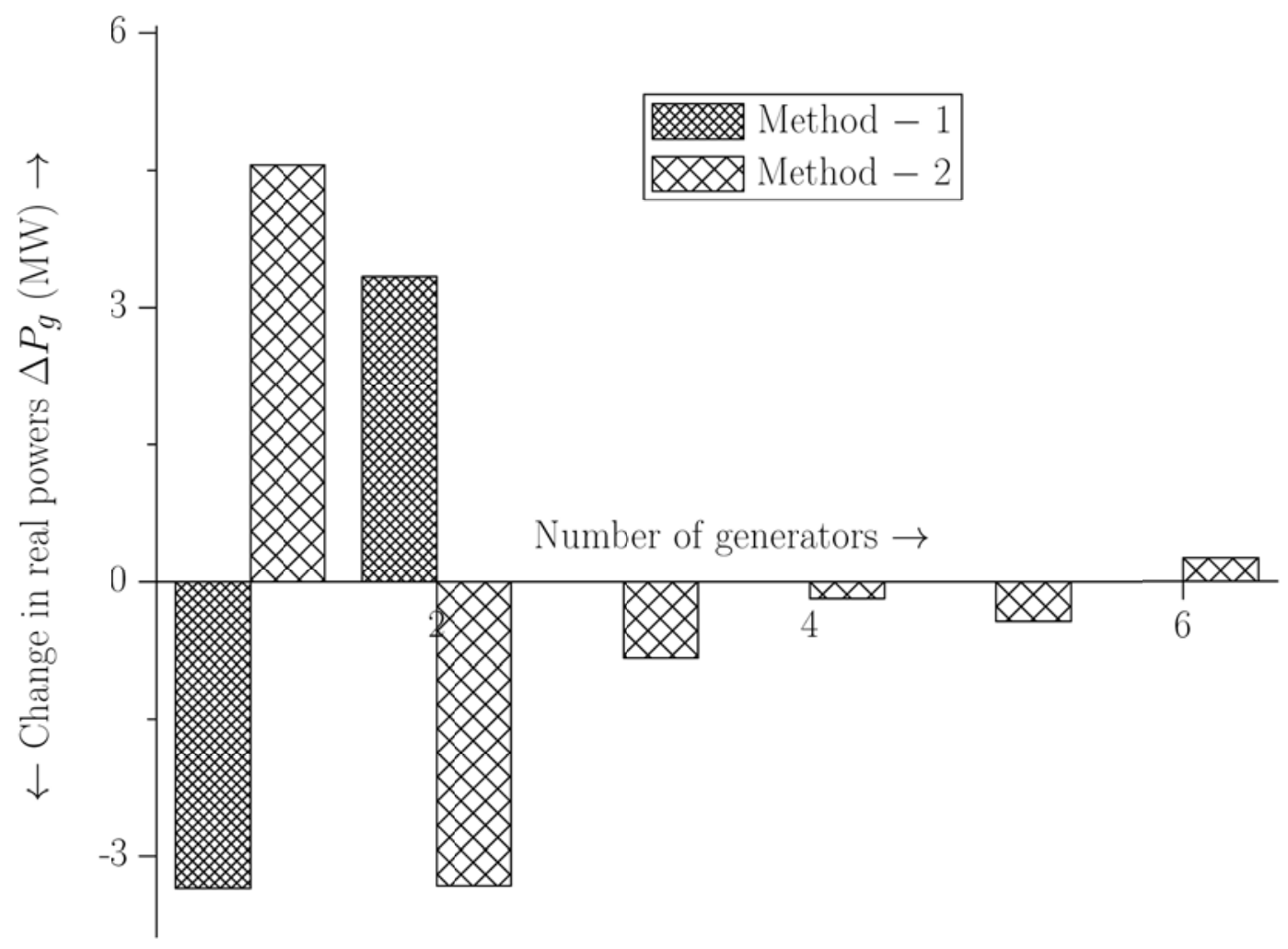

Figure 8. Rescheduled powers of participating generators 


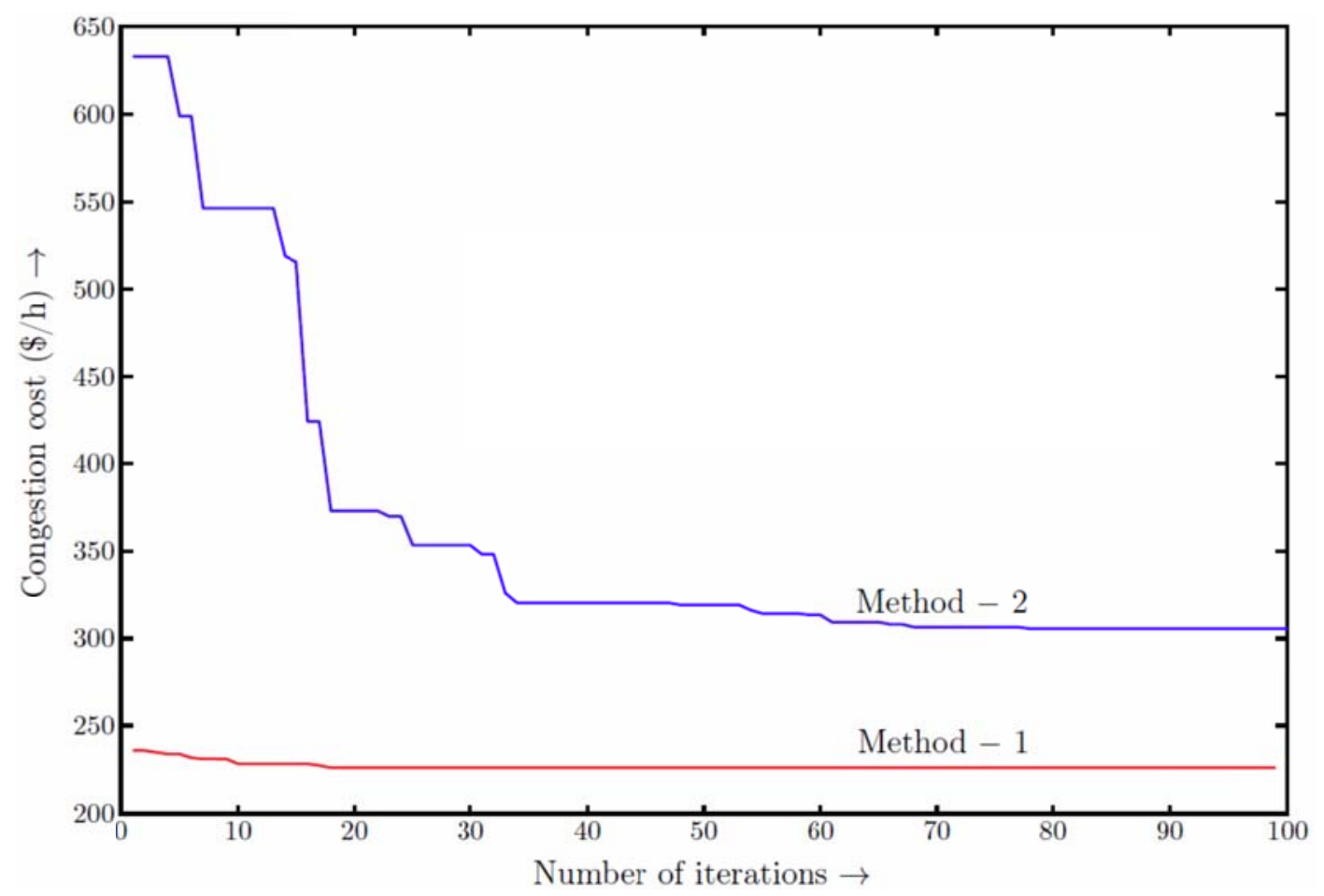

Figure 9. Convergence characteristics of intra zonal congestion

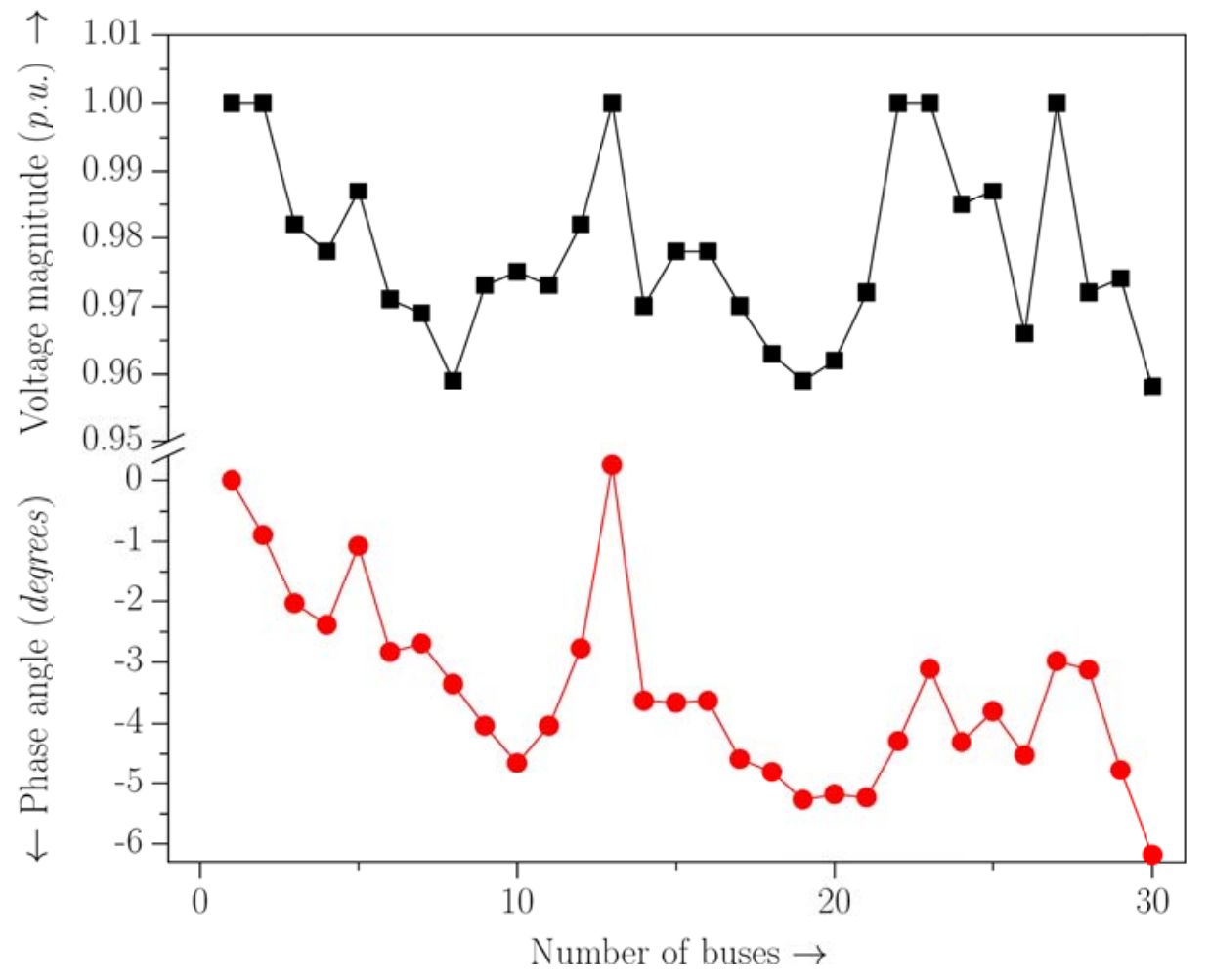

Figure 10. Phase angle and voltage magnitude of each bus 


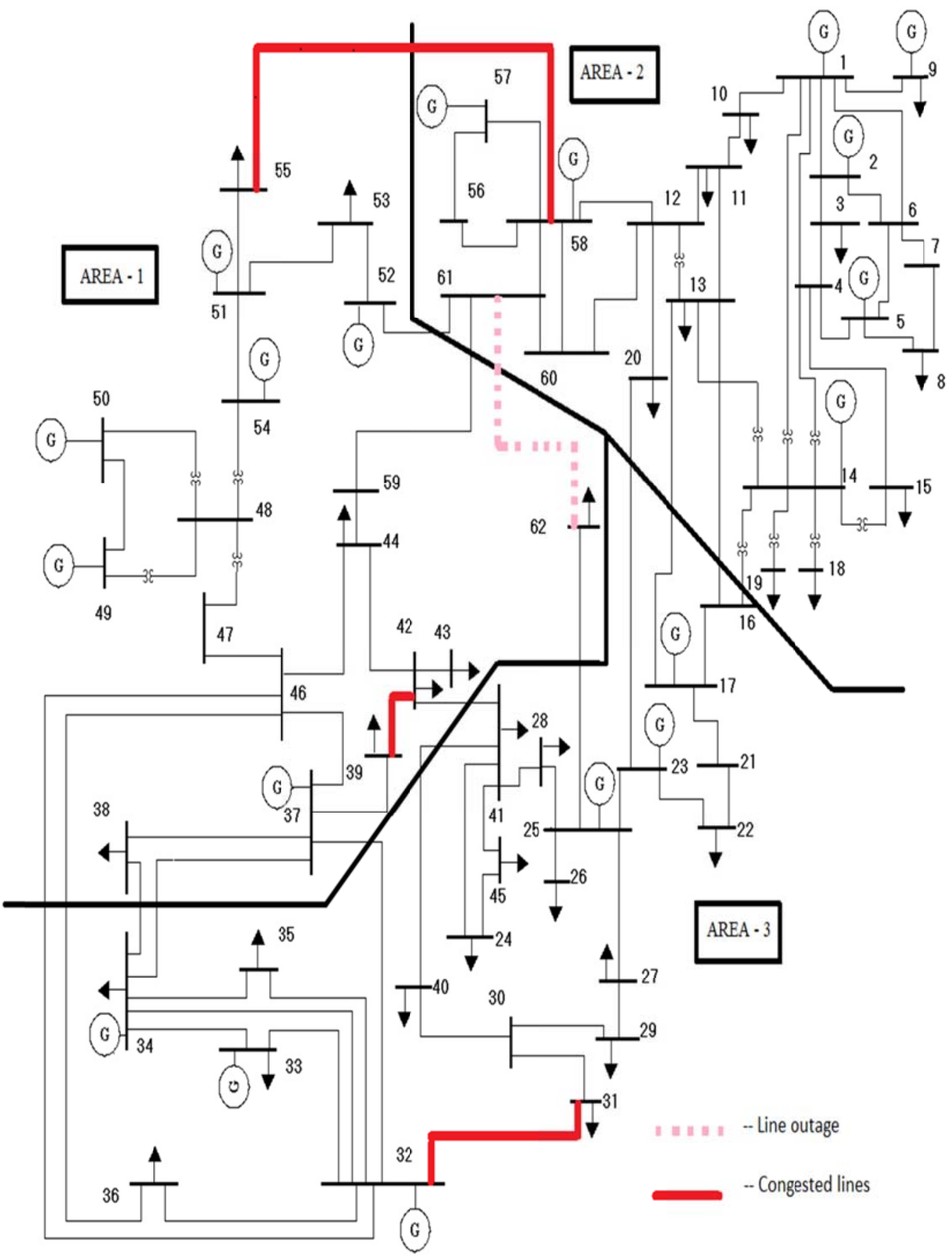

Figure 11. One line diagram of Indian utility 62 bus system showing line outages and congested lines 


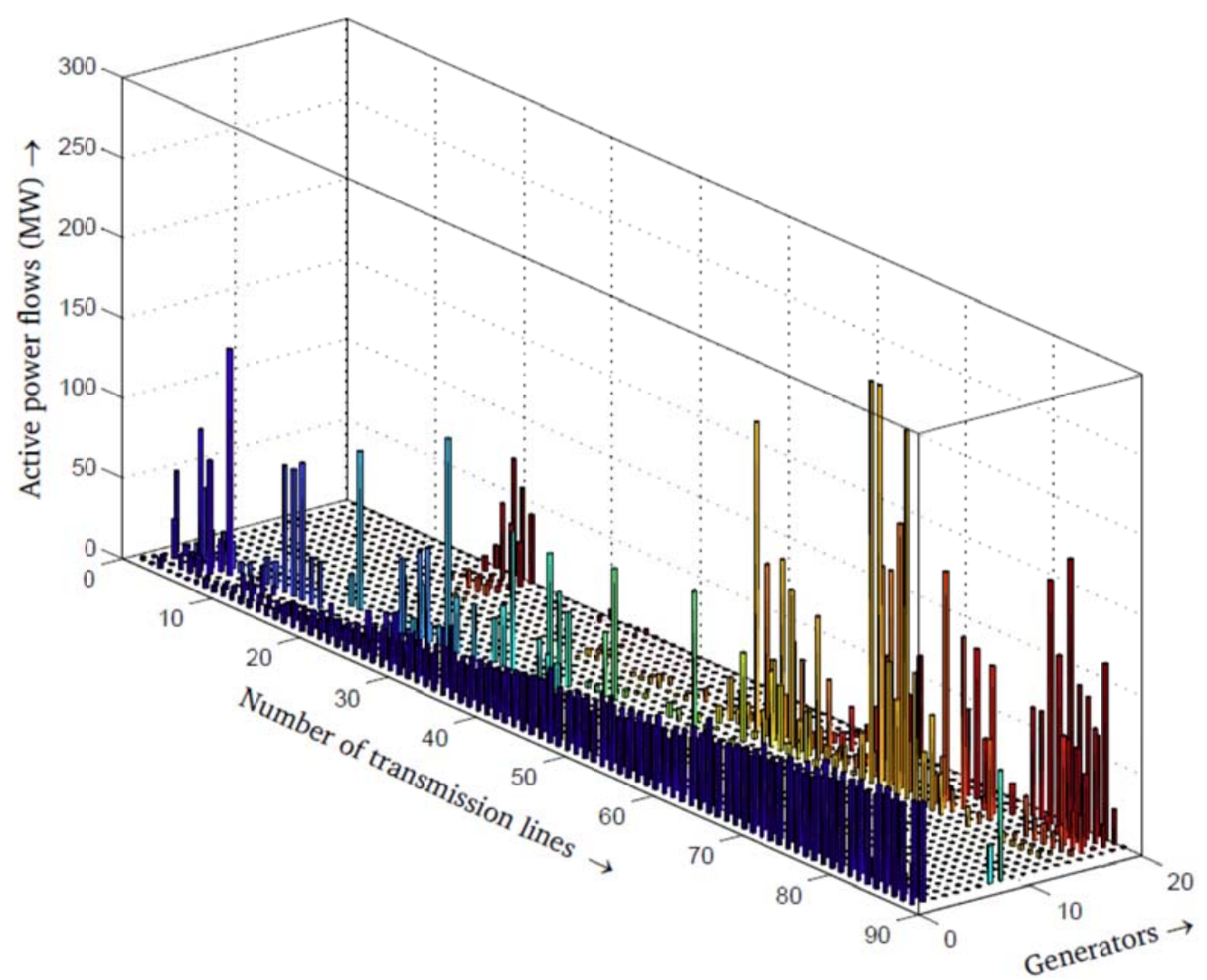

Figure 12. Contribution of generators to each transmission line

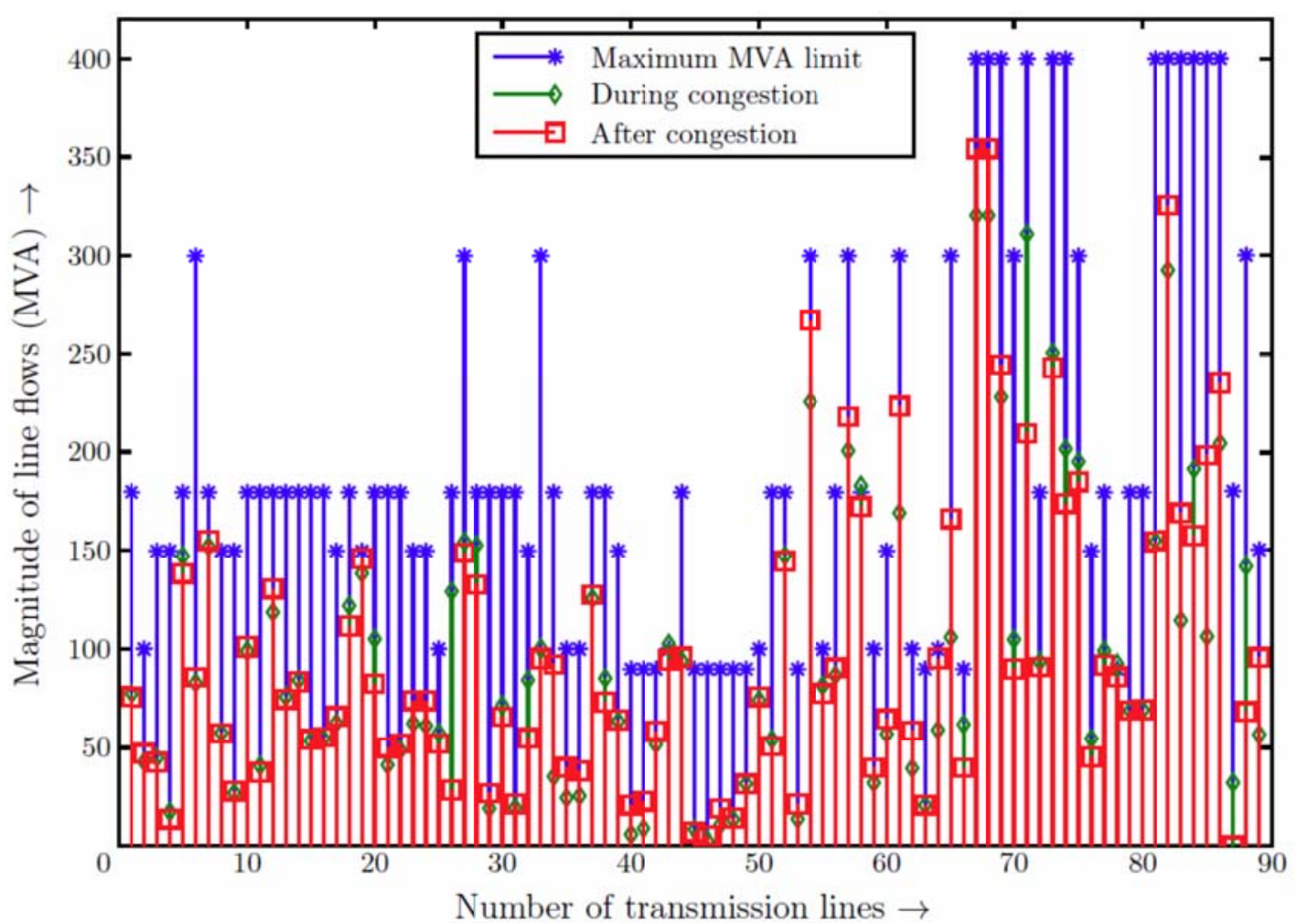

Figure 13. Power flows in each transmission line 


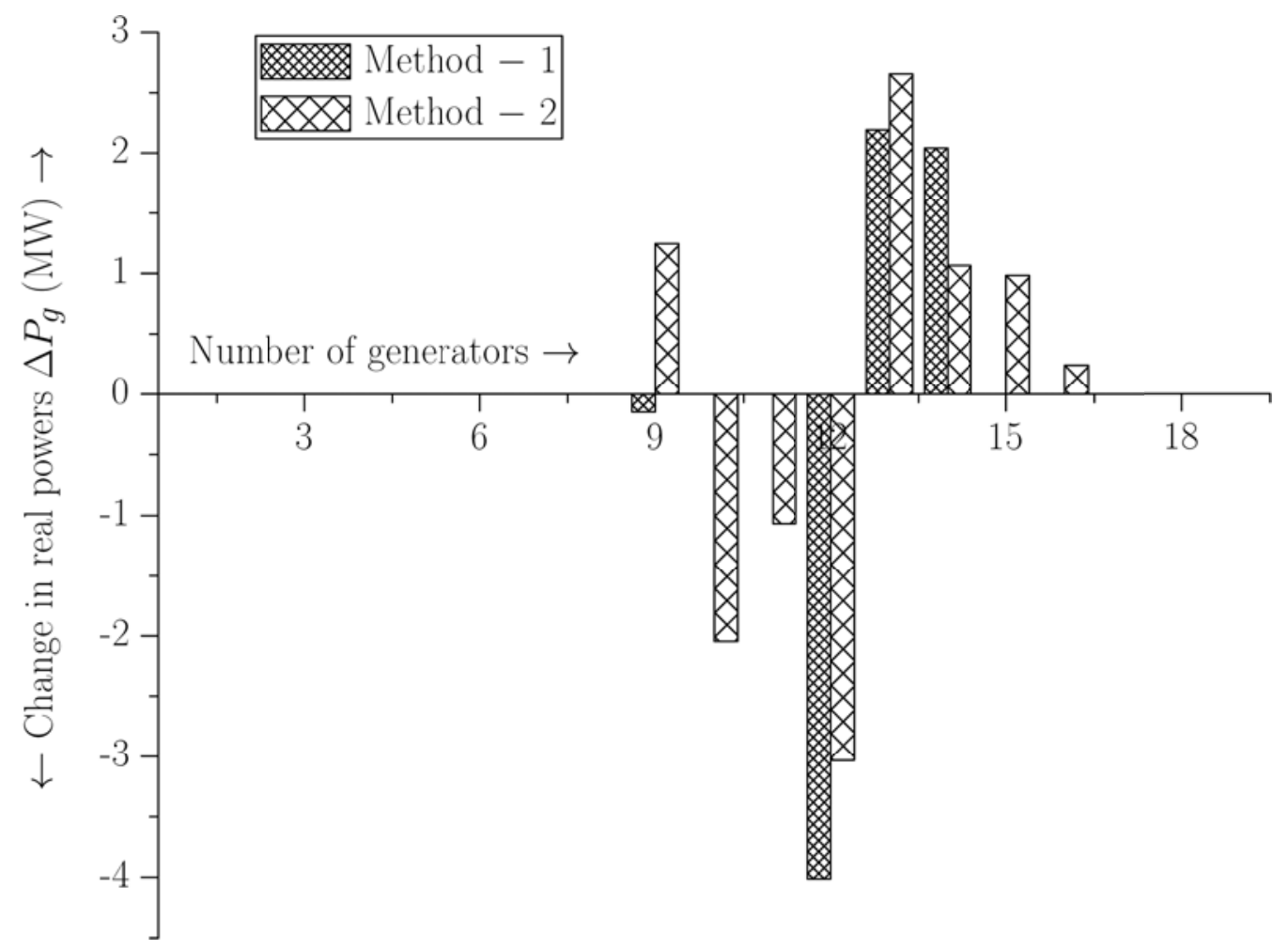

Figure 14. Rescheduled powers of participating generators

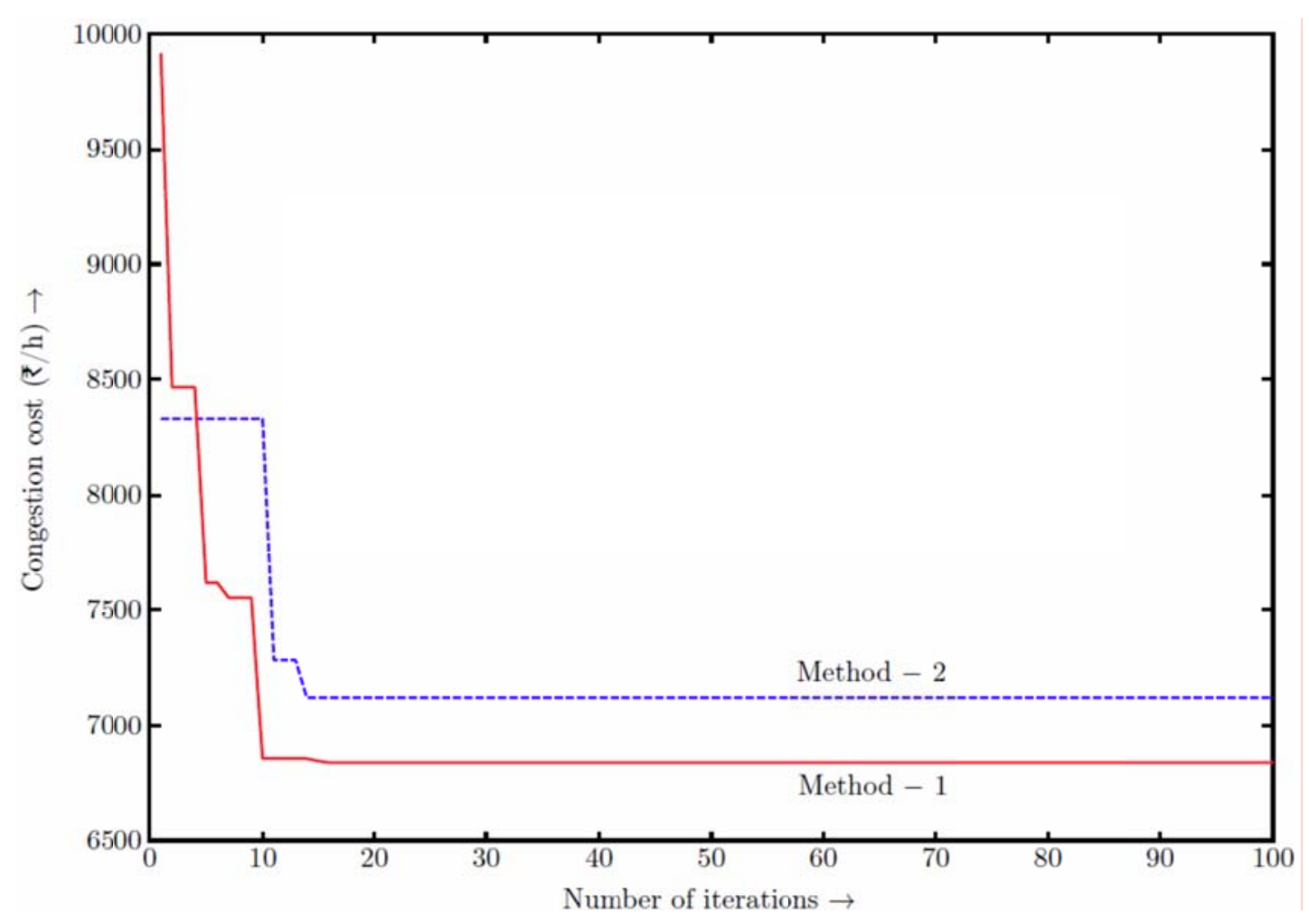

Figure 15. Convergence characteristics 


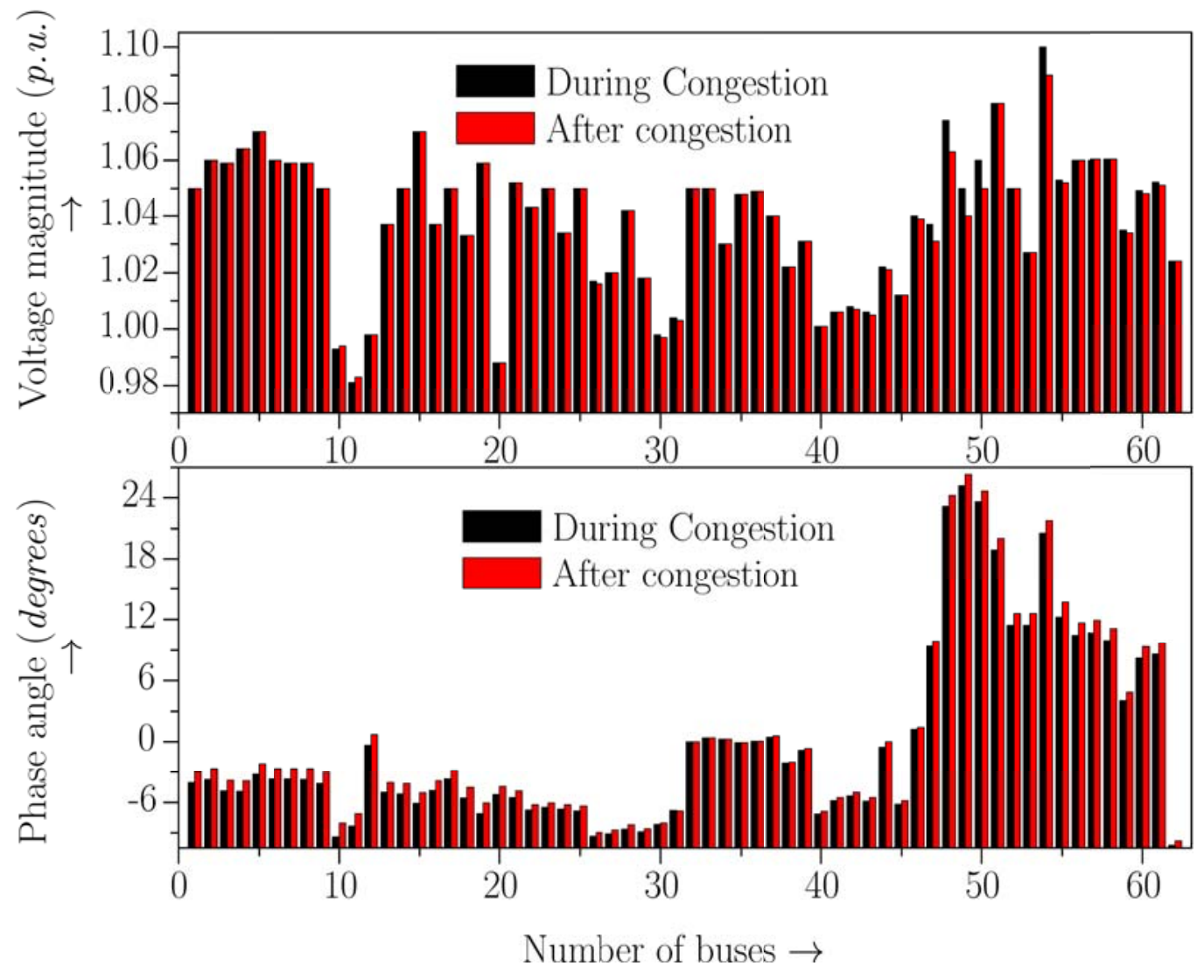

Figure 16. Phase angle and voltage magnitude of each bus

\section{References}

[1]. Ashwani Kumar, S. C. Srivastava, and S. N. Singh. Congestion management in competitive power market: A bibiliographical survey. Electric Power Systems Research, 76 (1-3):153-164, July 2005.

[2]. E. Bombard, P. Correia, G. Gross, and M. Amelin. Congestion management schemes: A com- parative analysis under a unified framework. IEEE Transactions on Power Systems, 18 (1):346-352, February 2003.

[3]. B. Chong, X. P. Zhang, K. R. Godfrey, L. Yao, and M. Bazargan. Congestion management of electricity markets using FACTS controllers. In IEEE Power Engineering Society Transmission and Distribution Conference \& Exhibition, pages 1 - 6, Asia - Pacific, Dalian, China, June 2005.

[4]. B. Chong, X. P. Zhang, K. R. Godfrey, L. Yao, and M. Bazargan. Optimal location of unified power flow controllers. European Transactions on Electrical Power, 20(5):601 - 610, July 2010.

[5]. K. Mwanza, S. You, and L. A. Tuan. Economic evaluation of FACTS for congestion management in pool markets. In Power Tech, pages 2053 - 2058, Lausanne, Switzerland, July 2007. Siemens.

[6]. K. R. S. Reddy, N. P. Padhy, and R. N. Patel. Congestion management in deregulated power system using FACTS devices. In Power India Conference, pages $1-8$, New Delhi, India, April 14 - 162006.

[7]. Naresh Acharya and N. Mitulananthan. Locating series FACTS devices for congestion man- agement in deregulated electricity markets. Electric Power Systems Research, 77 (3 - 4):352 -360, March 2007.

[8]. S. N. Singh and A. K. David. Optimal location of FACTS devices for congestion management. Electric Power Systems Research, 58(2):71 - 79, June 2001.

[9]. K. S. Verma, S. N. Singh, and H. O. Gupta. Location of unified power flow controller for congestion management. Electric Power Systems Research, 58(2):89 - 96, June 2001.

[10]. F. C. Schhweppe, M. C. Caramanis, R. D. Tabors, and R. E. Bohn. Spot pricing of Electricity. Kluwer, 1988.

[11]. W. W. Hogan. Contract networks for electric power transmission. Journal of Regulatory Economics, 4(3):211-242, September 1992. 
[12]. R. D. Christie, B. F. Wollenberg, and I. Wangensteen. Transmission management in the deregulated environment. Proceedings of IEEE, 88(2):170-195, February 2000.

[13]. J. Conejo, A. Milano, and R. G. Bertrand. Congestion management ensuring voltage stability. IEEE Transactions on Power Systems, 21(1):357-364, February 2006.

[14]. R. S. Fang and A. K. David. Transmission congestion management in an electricity market. IEEE Transactions on Power Systems, 14(2):877 - 883, August 1999.

[15]. Ashwani Kumar, S. C. Srivastava, and S. N. Singh. A zonal congestion management using ac transmission congestion distribution factors. Electric Power Systems Research, 72(1):85-93, November 2004.

[16]. Ashwani Kumar, S. C. Srivastava, and S. N. Singh. A zonal congestion management approach using real and reactive power rescheduling. IEEE Transactions on Power Systems, 19(1):554-562, February 2004.

[17]. G. Yseuratnam and D. Thukaram. Congestion management in open access based on relative electrical distance using voltage stability criteria. Electric Power Systems Research, 77(12):1608-1618, October 2007.

[18]. Sudipta Dutta and S. P. Singh. Optimal rescheduling of generator for congestion management based on particle swarm intelligence. IEEE Transactions on Power Systems, 23 (4):1560-1569, November 2008.

[19]. J. Bialek. Tracing the flow of electricity. IEE proceedings on Generation, Transmission and Distribution, 143(4):313-320, July 1996.

[20]. J. Bialek. Identification of source-sink connections in transmission networks. In Fourth International Conference on Power System Control and Management, pages 200-204, London, UK, April, 16-18 1996.

[21]. J. Bialek and D. B. Tam. Tracing the generator's output. In International Conference on Opportunities and Advances in International Electric Power Generation, pages 133-136, 1996.

[22]. E. Muneender and D. M. Vinod Kumar. A zonal congestion management using particle swarm intelligence and real coded genetic algorithm. In Power Systems Conference \& Exposition, pages 24-30, Marriott Marquis, Atlanta, USA, March 15 -18 2009.

[23]. R. Gnanadass, Narayana Prasad Padhy, and T. G. Palanivelu. A new method for the transmission congestion management in the restructured power market. Electrika Journal of Electrical Engineering, 9(1):52-58, March 2007.

[24]. J. Hazra and K. A. Sinha. Congestion management using multi objective particle swarm optimization. IEEE Transactions on Power Systems, 22(4):1726-1734, November 2007.

[25]. K. Price. Differential evolution: A fast and simple numerical optimizer. In Biennial conference of the North American Fuzzy Information Processing Society, pages 524-527, Berkeley, California, USA, June 19 - 22 1996. North American Fuzzy Information Processing Society.

[26]. K. Price and M. Storn. An introduction to differential evolution. In New optimization (Eds), pages 79-108. McGraw Hill International (UK) Limited, London, UK, 1999.

[27]. Hadi Saadat. Power System Analysis. Tata McGraw Hill International (UK) Limited, January 2002.

[28]. R. Gnanadass, Narayana Prasad Padhy, and K. Manivannan. Assessment of available transfer capability for practical power systems with combined economic emission dispatch. Electric Power Systems Research, 69(2-3):267 - 276, May 2004. 


\begin{tabular}{|c|c|c|c|c|c|c|c|c|c|c|c|c|c|c|c|c|c|c|c|c|}
\hline \multirow{2}{*}{$\begin{array}{l}\text { Line } \\
\text { no. }\end{array}$} & \multirow{2}{*}{ Bus } & \multicolumn{19}{|c|}{ Contribution factor (D) } \\
\hline & & $\mathrm{G}_{1}$ & $\mathrm{G}_{2}$ & $\mathrm{G}_{3}$ & $\mathrm{G}_{4}$ & $\mathrm{G}_{5}$ & $\mathrm{G}_{6}$ & $\mathrm{G}_{7}$ & $\mathrm{G}_{8}$ & G9 & $\mathrm{G}_{10}$ & $\mathrm{G}_{11}$ & $\mathrm{G}_{12}$ & $\mathrm{G}_{13}$ & $\mathrm{G}_{14}$ & $\mathrm{G}_{15}$ & $\mathrm{G}_{16}$ & $\mathrm{G}_{17}$ & $\mathrm{G}_{18}$ & $\mathrm{G}_{19}$ \\
\hline 1 & $2 \rightarrow 1$ & 0 & 0.260 & 0.009 & 0 & 0 & 0 & 0 & 0 & 0 & 0 & 0 & 0 & 0 & 0 & 0 & 0 & 0 & 0 & 0 \\
\hline 2 & $1 \rightarrow 4$ & 0.127 & 0.033 & 0.022 & 0 & 0 & 0 & 0 & 0 & 0 & 0 & 0 & 0 & 0 & 0 & 0 & 0 & 0 & 0 & 0 \\
\hline 3 & $6 \rightarrow 1$ & 0 & 0 & 0.164 & 0 & 0 & 0 & 0 & 0 & 0 & 0 & 0 & 0 & 0 & 0 & 0 & 0 & 0 & 0 & 0 \\
\hline 4 & $1 \rightarrow 9$ & 0.045 & 0.012 & 0.008 & 0 & 0 & 0 & 0 & 0 & 0 & 0 & 0 & 0 & 0 & 0 & 0 & 0 & 0 & 0 & 0 \\
\hline 5 & $1 \rightarrow 10$ & 0.458 & 0.119 & 0.079 & 0 & 0 & 0 & 0 & 0 & 0 & 0 & 0 & 0 & 0 & 0 & 0 & 0 & 0 & 0 & 0 \\
\hline 6 & $1 \rightarrow 14$ & 0.37 & 0.096 & 0.064 & 0 & 0 & 0 & 0 & 0 & 0 & 0 & 0 & 0 & 0 & 0 & 0 & 0 & 0 & 0 & 0 \\
\hline 7 & $2 \rightarrow 3$ & 0 & 0.74 & 0.024 & 0 & 0 & 0 & 0 & 0 & 0 & 0 & 0 & 0 & 0 & 0 & 0 & 0 & 0 & 0 & 0 \\
\hline 8 & $6 \rightarrow 2$ & 0 & 0 & 0.033 & 0 & 0 & 0 & 0 & 0 & 0 & 0 & 0 & 0 & 0 & 0 & 0 & 0 & 0 & 0 & 0 \\
\hline 9 & $4 \rightarrow 3$ & 0.002 & 0 & 0.005 & 0 & 0 & 0 & 0 & 0 & 0 & 0 & 0 & 0 & 0 & 0 & 0 & 0 & 0 & 0 & 0 \\
\hline 10 & $5 \rightarrow 4$ & 0.022 & 0.006 & 0.065 & 0 & 0 & 0 & 0 & 0 & 0 & 0 & 0 & 0 & 0 & 0 & 0 & 0 & 0 & 0 & 0 \\
\hline 11 & $4 \rightarrow 14$ & 0.022 & 0.006 & 0.065 & 0 & 0 & 0 & 0 & 0 & 0 & 0 & 0 & 0 & 0 & 0 & 0 & 0 & 0 & 0 & 0 \\
\hline 12 & $4 \rightarrow 15$ & 0.104 & 0.027 & 0.309 & 0 & 0 & 0 & 0 & 0 & 0 & 0 & 0 & 0 & 0 & 0 & 0 & 0 & 0 & 0 & 0 \\
\hline 13 & $5 \rightarrow 6$ & 0 & 0 & 0.309 & 0 & 0 & 0 & 0 & 0 & 0 & 0 & 0 & 0 & 0 & 0 & 0 & 0 & 0 & 0 & 0 \\
\hline 14 & $5 \rightarrow 8$ & 0 & 0 & 0.334 & 0 & 0 & 0 & 0 & 0 & 0 & 0 & 0 & 0 & 0 & 0 & 0 & 0 & 0 & 0 & 0 \\
\hline 15 & $6 \rightarrow 7$ & 0 & 0 & 0.113 & 0 & 0 & 0 & 0 & 0 & 0 & 0 & 0 & 0 & 0 & 0 & 0 & 0 & 0 & 0 & 0 \\
\hline 16 & $7 \rightarrow 8$ & 0 & 0 & 0.113 & 0 & 0 & 0 & 0 & 0 & 0 & 0 & 0 & 0 & 0 & 0 & 0 & 0 & 0 & 0 & 0 \\
\hline 17 & $11 \rightarrow 10$ & 0 & 0 & 0 & 0 & 0 & 0.094 & 0 & 0 & 0 & 0 & 0 & 0 & 0.002 & 0.002 & 0.008 & 0.012 & 0.008 & 0.041 & 0.041 \\
\hline 18 & $16 \rightarrow 11$ & 0 & 0 & 0 & 0 & 0 & 0.493 & 0 & 0 & 0 & 0 & 0 & 0 & 0 & 0 & 0 & 0 & 0 & 0 & 0 \\
\hline 19 & $12 \rightarrow 11$ & 0 & 0 & 0 & 0 & 0 & 0 & 0 & 0 & 0 & 0 & 0 & 0 & 0.008 & 0.008 & 0.043 & 0.062 & 0.043 & 0.213 & 0.213 \\
\hline 20 & $12 \rightarrow 13$ & 0 & 0 & 0 & 0 & 0 & 0 & 0 & 0 & 0 & 0 & 0 & 0 & 0.007 & 0.007 & 0.034 & 0.048 & 0.034 & 0.166 & 0.166 \\
\hline 21 & $12 \rightarrow 20$ & 0 & 0 & 0 & 0 & 0 & 0 & 0 & 0 & 0 & 0 & 0 & 0 & 0.005 & 0.005 & 0.026 & 0.036 & 0.026 & 0.126 & 0.126 \\
\hline 22 & $14 \rightarrow 13$ & 0.004 & 0.001 & 0.001 & 0 & 0.01 & 0.002 & 0 & 0 & 0 & 0 & 0 & 0 & 0 & 0 & 0 & 0 & 0 & 0 & 0 \\
\hline 23 & $17 \rightarrow 13$ & 0 & 0 & 0 & 0 & 0 & 0.167 & 0 & 0 & 0 & 0 & 0 & 0 & 0 & 0 & 0 & 0 & 0 & 0 & 0 \\
\hline 24 & $14 \rightarrow 15$ & 0.111 & 0.029 & 0.036 & 0 & 0.284 & 0.047 & 0 & 0 & 0 & 0 & 0 & 0 & 0 & 0 & 0 & 0 & 0 & 0 & 0 \\
\hline 25 & $16 \rightarrow 14$ & 0 & 0 & 0 & 0 & 0 & 0.165 & 0 & 0 & 0 & 0 & 0 & 0 & 0 & 0 & 0 & 0 & 0 & 0 & 0 \\
\hline 26 & $14 \rightarrow 18$ & 0.133 & 0.035 & 0.043 & 0 & 0.338 & 0.056 & 0 & 0 & 0 & 0 & 0 & 0 & 0 & 0 & 0 & 0 & 0 & 0 & 0 \\
\hline 27 & $14 \rightarrow 19$ & 0.144 & 0.037 & 0.047 & 0 & 0.367 & 0.061 & 0 & 0 & 0 & 0 & 0 & 0 & 0 & 0 & 0 & 0 & 0 & 0 & 0 \\
\hline 28 & $17 \rightarrow 16$ & 0 & 0 & 0 & 0 & 0 & 0.657 & 0 & 0 & 0 & 0 & 0 & 0 & 0 & 0 & 0 & 0 & 0 & 0 & 0 \\
\hline 29 & $17 \rightarrow 21$ & 0 & 0 & 0 & 0 & 0 & 0.176 & 0 & 0 & 0 & 0 & 0 & 0 & 0 & 0 & 0 & 0 & 0 & 0 & 0 \\
\hline 30 & $20 \rightarrow 23$ & 0 & 0 & 0 & 0 & 0 & 0 & 0 & 0 & 0 & 0 & 0 & 0 & 0.001 & 0.001 & 0.003 & 0.005 & 0.003 & 0.016 & 0.016 \\
\hline 31 & $21 \rightarrow 22$ & 0 & 0 & 0 & 0 & 0 & 0.176 & 0 & 0 & 0 & 0 & 0 & 0 & 0 & 0 & 0 & 0 & 0 & 0 & 0 \\
\hline 32 & $23 \rightarrow 22$ & 0 & 0 & 0 & 0 & 0 & 0 & 0.181 & 0 & 0 & 0 & 0 & 0 & 0 & 0 & 0.001 & 0.001 & 0.001 & 0.003 & 0.003 \\
\hline
\end{tabular}

Table 5. Active power flow contribution factor of generators to the transmission lines - multiline contingency 
Table 5. Continued from previous page

\begin{tabular}{|c|c|c|c|c|c|c|c|c|c|c|c|c|c|c|c|c|c|c|c|c|}
\hline \multirow{2}{*}{$\begin{array}{c}\text { Line } \\
\text { no. }\end{array}$} & \multirow{2}{*}{ Bus } & \multicolumn{19}{|c|}{ Contribution factor $(D)$} \\
\hline & & $\mathrm{G}_{1}$ & $\mathrm{G}_{2}$ & $\mathrm{G}_{3}$ & $G_{4}$ & $\mathrm{G}_{5}$ & $\mathrm{G}_{6}$ & $\mathrm{G}_{7}$ & $\mathrm{G}_{8}$ & G9 & $G_{10}$ & $G_{11}$ & $G_{12}$ & $G_{13}$ & $G_{14}$ & $G_{15}$ & $G_{16}$ & $G_{17}$ & $G_{18}$ & $G_{19}$ \\
\hline 33 & $23 \rightarrow 24$ & 0 & 0 & 0 & 0 & 0 & 0 & 0.249 & 0 & 0 & 0 & 0 & 0 & 0 & 0 & 0.001 & 0.001 & 0.001 & 0.004 & 0.004 \\
\hline 34 & $23 \rightarrow 25$ & 0 & 0 & 0 & 0 & 0 & 0 & 0.57 & .0 & 0 & 0 & 0 & 0 & 0 & 0 & 0.002 & 0.003 & 0.002 & 0.009 & 0.009 \\
\hline 35 & $41 \rightarrow 24$ & 0 & 0 & 0 & 0 & 0 & 0 & 0 & 0 & 0 & 0 & 0 & 0.02 & 0.015 & 0.015 & 0.001 & 0.014 & 0.001 & 0.004 & 0.004 \\
\hline 36 & $45 \rightarrow 24$ & 0 & 0 & 0 & 0 & 0 & 0 & 0 & 0 & 0 & 0 & 0 & 0.012 & 0.009 & 0.009 & 0 & 0.008 & 0 & 0.002 & 0.002 \\
\hline 37 & $25 \rightarrow 26$ & 0 & 0 & 0 & 0 & 0 & 0 & 0.179 & 0.313 & 0 & 0 & 0 & 0 & 0 & 0 & 0.001 & 0.001 & 0.001 & 0.003 & 0.003 \\
\hline 38 & $25 \rightarrow 27$ & 0 & 0 & 0 & 0 & 0 & 0 & 0.129 & 0.226 & 0 & 0 & 0 & 0 & 0 & 0 & 0 & 0.001 & 0 & 0.002 & 0.002 \\
\hline 39 & $25 \rightarrow 28$ & 0 & 0 & 0 & 0 & 0 & 0 & 0.106 & 0.186 & 0 & 0 & 0 & 0 & 0 & 0 & 0 & 0 & 0 & 0.002 & 0.002 \\
\hline 40 & $29 \rightarrow 27$ & 0 & 0 & 0 & 0 & 0 & 0 & 0 & 0 & 0.02 & 0.003 & 0 & 0.008 & 0.007 & 0.007 & 0 & 0.005 & 0 & 0.001 & 0.001 \\
\hline 41 & $30 \rightarrow 29$ & 0 & 0 & 0 & 0 & 0 & 0 & 0 & 0 & 0.02 & 0.003 & 0 & 0.008 & 0.007 & 0.007 & 0 & 0.005 & 0 & 0.001 & 0.001 \\
\hline 42 & $31 \rightarrow 30$ & 0 & 0 & 0 & 0 & 0 & 0 & 0 & 0 & 0.23 & 0.033 & 0.005 & 0.004 & 0.013 & 0.013 & 0 & 0 & 0 & 0 & 0 \\
\hline 43 & $32 \rightarrow 30$ & $\mathbf{0}$ & $\mathbf{0}$ & $\mathbf{0}$ & $\mathbf{0}$ & $\mathbf{0}$ & $\mathbf{0}$ & $\mathbf{0}$ & $\mathbf{0}$ & 0.483 & 0.068 & 0.002 & 0.200 & 0.025 & 0.040 & $\mathbf{0}$ & $\mathbf{0}$ & $\mathbf{0}$ & $\mathbf{0}$ & $\mathbf{0}$ \\
\hline 44 & $34 \rightarrow 31$ & 0 & 0 & 0 & 0 & 0 & 0 & 0 & 0 & 0.476 & 0.069 & 0.009 & 0.008 & 0.027 & 0.027 & 0 & 0 & 0 & 0 & 0 \\
\hline 45 & $36 \rightarrow 32$ & 0 & 0 & 0 & 0 & 0 & 0 & 0 & 0 & 0 & 0.002 & 0.02 & 0.003 & 0.002 & 0.002 & 0 & 0 & 0 & 0 & 0 \\
\hline 46 & $37 \rightarrow 32$ & 0 & 0 & 0 & 0 & 0 & 0 & 0 & 0 & 0 & 0 & 0 & 0 & 0.003 & 0.003 & 0 & 0 & 0 & 0 & 0 \\
\hline 47 & $46 \rightarrow 32$ & 0 & 0 & 0 & 0 & 0 & 0 & 0 & 0 & 0 & 0 & 0 & 0.014 & 0.009 & 0.009 & 0 & 0 & 0 & 0 & 0 \\
\hline 48 & $33 \rightarrow 32$ & 0 & 0 & 0 & 0 & 0 & 0 & 0 & 0 & 0 & 0 & 0 & 0 & 0.043 & 0.043 & 0 & 0 & 0 & 0 & 0 \\
\hline 49 & $33 \rightarrow 32$ & 0 & 0 & 0 & 0 & 0 & 0 & 0 & 0 & 0 & 0.142 & 0 & 0 & 0 & 0 & 0 & 0 & 0 & 0 & 0 \\
\hline 50 & $34 \rightarrow 34$ & 0 & 0 & 0 & 0 & 0 & 0 & 0 & 0 & 0 & 0.12 & 0 & 0 & 0 & 0 & 0 & 0 & 0 & 0 & 0 \\
\hline 51 & $37 \rightarrow 35$ & 0 & 0 & 0 & 0 & 0 & 0 & 0 & 0 & 0 & 0.005 & 0.04 & 0.005 & 0.003 & 0.003 & 0 & 0 & 0 & 0 & 0 \\
\hline 52 & $32 \rightarrow 35$ & 0 & 0 & 0 & 0 & 0 & 0 & 0 & 0 & 0.524 & 0.075 & 0.01 & 0.009 & 0.03 & 0.03 & 0 & 0 & 0 & 0 & 0 \\
\hline 53 & $46 \rightarrow 36$ & 0 & 0 & 0 & 0 & 0 & 0 & 0 & 0 & 0 & 0 & 0 & 0 & 0.049 & 0.049 & 0 & 0 & 0 & 0 & 0 \\
\hline 54 & $46 \rightarrow 37$ & 0 & 0 & 0 & 0 & 0 & 0 & 0 & 0 & 0 & 0 & 0 & 0 & 0.622 & 0.622 & 0 & 0 & 0 & 0 & 0 \\
\hline 55 & $34 \rightarrow 38$ & 0 & 0 & 0 & 0 & 0 & 0 & 0 & 0 & 0 & 0.049 & 0.41 & 0.055 & 0.034 & 0.034 & 0 & 0 & 0 & 0 & 0 \\
\hline 56 & $37 \rightarrow 38$ & 0 & 0 & 0 & 0 & 0 & 0 & 0 & 0 & 0 & 0 & 0 & 0.255 & 0.159 & 0.159 & 0 & 0 & 0 & 0 & 0 \\
\hline 57 & $37 \rightarrow 39$ & 0 & 0 & 0 & 0 & 0 & 0 & 0 & 0 & 0 & 0 & 0 & 0.595 & 0.37 & 0.37 & 0 & 0 & 0 & 0 & 0 \\
\hline 58 & $39 \rightarrow 42$ & 0 & 0 & 0 & 0 & 0 & 0 & 0 & 0 & 0 & 0 & 0 & 0.511 & 0.316 & 0.332 & 0 & 0 & 0 & 0 & 0 \\
\hline 59 & $40 \rightarrow 30$ & 0 & 0 & 0 & 0 & 0 & 0 & 0 & 0 & 0 & 0 & 0 & 0.086 & 0.062 & 0.062 & 0.003 & 0.059 & 0.003 & 0.016 & 0.016 \\
\hline 60 & $41 \rightarrow 40$ & 0 & 0 & 0 & 0 & 0 & 0 & 0 & 0 & 0 & 0 & 0 & 0.131 & 0.094 & 0.094 & 0.005 & 0.089 & 0.005 & 0.024 & 0.024 \\
\hline 61 & $42 \rightarrow 41$ & 0 & 0 & 0 & 0 & 0 & 0 & 0 & 0 & 0 & 0 & 0 & 0.399 & 0.288 & 0.288 & 0.015 & 0.271 & 0.015 & 0.073 & 0.073 \\
\hline 62 & $41 \rightarrow 45$ & 0 & 0 & 0 & 0 & 0 & 0 & 0 & 0 & 0 & 0 & 0 & 0.048 & 0.035 & 0.035 & 0.002 & 0.033 & 0.002 & 0.009 & 0.009 \\
\hline 63 & $42 \rightarrow 43$ & 0 & 0 & 0 & 0 & 0 & 0 & 0 & 0 & 0 & 0 & 0 & 0.036 & 0.026 & 0.026 & 0.001 & 0.024 & 0.001 & 0.007 & 0.007 \\
\hline 64 & $44 \rightarrow 42$ & 0 & 0 & 0 & 0 & 0 & 0 & 0 & 0 & 0 & 0 & 0 & 0 & 0.051 & 0.051 & 0.019 & 0.346 & 0.019 & 0.094 & 0.094 \\
\hline 65 & $59 \rightarrow 44$ & 0 & 0 & 0 & 0 & 0 & 0 & 0 & 0 & 0 & 0 & 0 & 0 & 0.007 & 0.007 & 0.038 & 0.685 & 0.038 & 0.185 & 0.185 \\
\hline & & & & & & & & & & ied o & t pag & & & & & & & & & \\
\hline
\end{tabular}


Table 5. Continued from previous page

\begin{tabular}{|c|c|c|c|c|c|c|c|c|c|c|c|c|c|c|c|c|c|c|c|c|}
\hline \multirow{2}{*}{$\begin{array}{l}\text { Line } \\
\text { no. }\end{array}$} & \multirow{2}{*}{ Bus } & \multicolumn{19}{|c|}{ Contribution factor $(D)$} \\
\hline & & $\mathrm{G}_{1}$ & $\mathrm{G}_{2}$ & $\mathrm{G}_{3}$ & $G_{4}$ & $\mathrm{G}_{5}$ & $\mathrm{G}_{6}$ & $\mathrm{G}_{7}$ & $\mathrm{G}_{8}$ & G9 & $G_{10}$ & $G_{11}$ & $G_{12}$ & $G_{13}$ & $G_{14}$ & $G_{15}$ & $G_{16}$ & $G_{17}$ & $G_{18}$ & $G_{19}$ \\
\hline 66 & $46 \rightarrow 44$ & 0 & 0 & 0 & 0 & 0 & 0 & 0 & 0 & 0 & 0 & 0 & 0 & 0.093 & 0.093 & 0 & 0 & 0 & 0 & 0 \\
\hline 67 & $47 \rightarrow 46$ & 0 & 0 & 0 & 0 & 0 & 0 & 0 & 0 & 0 & 0 & 0 & 0 & 0.807 & 0.807 & 0 & 0 & 0 & 0 & 0 \\
\hline 68 & $48 \rightarrow 47$ & 0 & 0 & 0 & 0 & 0 & 0 & 0 & 0 & 0 & 0 & 0 & 0 & 0.807 & 0.807 & 0 & 0 & 0 & 0 & 0 \\
\hline 69 & $50 \rightarrow 48$ & 0 & 0 & 0 & 0 & 0 & 0 & 0 & 0 & 0 & 0 & 0 & 0 & 0.259 & 1 & 0 & 0 & 0 & 0 & 0 \\
\hline 70 & $48 \rightarrow 54$ & 0 & 0 & 0 & 0 & 0 & 0 & 0 & 0 & 0 & 0 & 0 & 0 & 0.193 & 0.193 & 0 & 0 & 0 & 0 & 0 \\
\hline 71 & $49 \rightarrow 48$ & 0 & 0 & 0 & 0 & 0 & 0 & 0 & 0 & 0 & 0 & 0 & 0 & 0.741 & 0 & 0 & 0 & 0 & 0 & 0 \\
\hline 72 & $49 \rightarrow 50$ & 0 & 0 & 0 & 0 & 0 & 0 & 0 & 0 & 0 & 0 & 0 & 0 & 0.259 & 0 & 0 & 0 & 0 & 0 & 0 \\
\hline 73 & $51 \rightarrow 53$ & 0 & 0 & 0 & 0 & 0 & 0 & 0 & 0 & 0 & 0 & 0 & 0 & 0.11 & 0.11 & 0.572 & 0 & 0.572 & 0 & 0 \\
\hline 74 & $54 \rightarrow 51$ & 0 & 0 & 0 & 0 & 0 & 0 & 0 & 0 & 0 & 0 & 0 & 0 & 0.193 & 0.193 & 0 & 0 & 1 & 0 & 0 \\
\hline 75 & $51 \rightarrow 55$ & 0 & 0 & 0 & 0 & 0 & 0 & 0 & 0 & 0 & 0 & 0 & 0 & 0.082 & 0.082 & 0.428 & 0 & 0.428 & 0 & 0 \\
\hline 76 & $52 \rightarrow 53$ & 0 & 0 & 0 & 0 & 0 & 0 & 0 & 0 & 0 & 0 & 0 & 0 & 0 & 0 & 0 & 0.08 & 0 & 0 & 0 \\
\hline 77 & $52 \rightarrow 61$ & 0 & 0 & 0 & 0 & 0 & 0 & 0 & 0 & 0 & 0 & 0 & 0 & 0 & 0 & 0 & 0.92 & 0 & 0 & 0 \\
\hline 78 & $55 \rightarrow 58$ & O & $\mathbf{0}$ & O & 0 & $\mathbf{0}$ & O & 0 & 0 & $\mathbf{0}$ & 0 & 0.040 & 0.040 & 0.022 & 0.027 & 0 & O & 0 & o & $\mathbf{0}$ \\
\hline 79 & $56 \rightarrow 58$ & 0 & 0 & 0 & 0 & 0 & 0 & 0 & 0 & 0 & 0 & 0 & 0 & 0 & 0 & 0 & 0 & 0 & 0.308 & 0 \\
\hline 80 & $57 \rightarrow 56$ & 0 & 0 & 0 & 0 & 0 & 0 & 0 & 0 & 0 & 0 & 0 & 0 & 0 & 0 & 0 & 0 & 0 & 0.308 & 0 \\
\hline 81 & $57 \rightarrow 58$ & 0 & 0 & 0 & 0 & 0 & 0 & 0 & 0 & 0 & 0 & 0 & 0 & 0 & 0 & 0 & 0 & 0 & 0.692 & 0 \\
\hline 82 & $58 \rightarrow 12$ & 0 & 0 & 0 & 0 & 0 & 0 & 0 & 0 & 0 & 0 & 0 & 0 & 0.019 & 0.019 & 0.1 & 0 & 0.1 & 0.489 & 0.489 \\
\hline 83 & $58 \rightarrow 60$ & 0 & 0 & 0 & 0 & 0 & 0 & 0 & 0 & 0 & 0 & 0 & 0 & 0.01 & 0.01 & 0.053 & 0 & 0.053 & 0.262 & 0.262 \\
\hline 84 & $58 \rightarrow 61$ & 0 & 0 & 0 & 0 & 0 & 0 & 0 & 0 & 0 & 0 & 0 & 0 & 0.01 & 0.01 & 0.051 & 0 & 0.051 & 0.249 & 0.249 \\
\hline 85 & $61 \rightarrow 59$ & 0 & 0 & 0 & 0 & 0 & 0 & 0 & 0 & 0 & 0 & 0 & 0 & 0.007 & 0.007 & 0.038 & 0.685 & 0.038 & 0.185 & 0.185 \\
\hline 86 & $60 \rightarrow 12$ & 0 & 0 & 0 & 0 & 0 & 0 & 0 & 0 & 0 & 0 & 0 & 0 & 0.013 & 0.013 & 0.066 & 0.236 & 0.066 & 0.326 & 0.326 \\
\hline 87 & $61 \rightarrow 60$ & 0 & 0 & 0 & 0 & 0 & 0 & 0 & 0 & 0 & 0 & 0 & 0 & 0.003 & 0.003 & 0.013 & 0.236 & 0.013 & 0.064 & 0.064 \\
\hline 88 & $25 \rightarrow 62$ & 0 & 0 & 0 & 0 & 0 & 0 & 0.157 & 0.275 & 0 & 0 & 0 & 0 & 0 & 0 & 0.001 & 0.001 & 0.001 & 0.002 & 0.002 \\
\hline
\end{tabular}




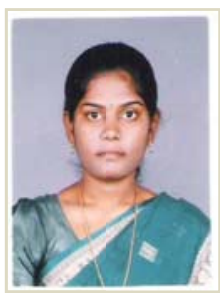

R. Rajathy obtained her B.E. in Electrical and Electronics Engineering and M. E. in power system with Distinction from Thiagarajar College of Engineering, Madurai and Ph.D. in Electrical Engineering from Pondicherry University, Pondicherry, India. She is now working as a faculty in the Department of Electrical and Electronics Engineering, Pondicherry Engineering College, Pondicherry, India. Her fields of interest are Power System Optimization and Power System Restructuring.

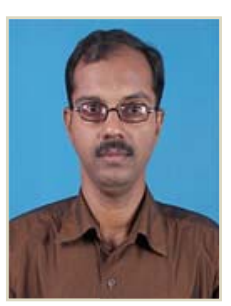

Harish Kumar obtained his $\mathrm{Ph}$. D. from Mangalore University, India and now working as a faculty in the Department of Physics, Pondicherry Engineering College, Pondicherry, INDIA. His fields of interest are Computational \& Theoretical Physics, Applied Physics and Optimization Techniques. 